\title{
Cultura jurídica chilena, derecho a la identidad cultural y jurisprudencia, un acercamiento metodológico interdisciplinario ${ }^{1}$
}

\author{
Chilean legal culture, right to cultural identity, and precedent; an interdiscipli- \\ nary methodological approach
}

Juan Jorge Faundes Peñafiel ${ }^{2}$

Universidad Autónoma de Chile, Chile

FABIEN Le BonNiEc ${ }^{3}$

Universidad Católica de Temuco, Chile

\begin{abstract}
RESUMEN EXaminamos las transformaciones o conflictos que se presentan en la cultura jurídica chilena, en relación con el derecho a la identidad cultural de pueblos indígenas y otros grupos. Al efecto, la investigación: (i) formula una metodología especializada, interdisciplinaria que comprende el estudio del campo jurídico en su conjunto: contexto, normas constitucionales, las prácticas de los operadores, sus comprensiones y cómo se reflejan en la jurisprudencia; (ii) aplicando dicha metodología, estudia las transformaciones o tensiones que se pueden identificar en la cultura jurídica chilena en relación con el derecho a la identidad cultural.
\end{abstract}

1. Realizado en el marco del: i) Proyecto Fondecyt Regular "Justicia e interculturalidad en la Macroregión sur de Chile. Un estudio de las transformaciones del campo jurídico y de la cultura jurídica chilena ante la emergencia del derecho a la identidad cultural" ( $\left.\mathrm{N}^{\circ} 1170505\right)$; ii) Proyecto "The contribution of the Ius Constitucionale Commune in América Latina (ICCAL) to a Euro-American dialogue on human rights, with focus on the fundamental right to cultural identity of minority groups" del Max Planck Institute for Comparative Public Law and International Law of Heidelberg (MPIL), Alemania (Visitig Scholar, Juan Jorge Faundes, enero-febrero 2020); iii) la estancia de investigación realizada por Juan Jorge Faundes (marzo-mayo 2019) en el Programa de Mestrado e Doutorado do Centro Universitário de Brasília -UniCEUB. Nuestros agradecimientos a la Profesora Doctora Patricia Perrone Campos Mello de dicho Programa, por sus valiosos aportes.

2. Académico del Instituto de Investigación en Derecho de la Facultad de Derecho de la Universidad Autónoma de Chile. Mail: juan.faundes@uautonoma.cl.

3. Profesor e investigador en el Departamento de Antropología y en el Núcleo de Investigación en Estudios Interétnicos e Interculturales de la Universidad Católica de Temuco. Mail: fabien@uct.cl. 
PALABRAS CLAVE Cultura jurídica chilena; Derecho identidad cultural; Jurisprudencia; Metodología.

ABSTRACT We study the transformations and conflicts related to recognition of the cultural identity of indigenous peoples and other groups in the legal culture of Chile. In pursuit of this object we: (i) develop a specific interdisciplinary methodology that includes study of the legal field as a whole: context, constitutional norms, the practices of operators, their understandings and how they are reflected in precedent; and (ii) use this methodology to study transformations and conflicts identifiable in Chilean legal culture which relate to cultural identity in Chile.

KEYWORDS Chilean legal culture; Right to cultural identity; Precedents, Methodology.

\section{Introducción}

En 1993 en Chile se promulgaba la Ley Indígena 19253, la cual introdujo un conjunto importante de instituciones que implicaban una apertura en el campo jurídico chileno a nuevas comprensiones en materia de derechos de los pueblos indígenas ${ }^{4}$. Más tarde, en 2007 se aprueba la Declaración de Naciones Unidas sobre Derechos de los Pueblos Indígenas (DNUDPI) y en 2008 el país ratificó el Convenio Nº169 de la OIT. Paralelamente, en los últimos 30 años los países de América Latina fueron alcanzando nuevas constituciones o realizaron reformas constitucionales, con el reconocimiento de la diversidad cultural, de derechos de los pueblos indígenas ${ }^{5}$ y de otros grupos vulnerables ${ }^{6}$, como los afrodescendientes. Estos cambios han introducido nuevos estatutos de derechos que configuran importantes transformaciones en el campo jurídico,

\footnotetext{
4. No abordamos aquí los alcances de esta ley, ni las críticas que en las últimas tres décadas se le han formulado, solo referimos a ella como un hito de partida para las nuevas comprensiones sobre los derechos indígenas en Chile. Sobre impactos de la Ley 19.253 en el ordenamiento jurídico chileno v. ESPINOZA (2017).

5. YRIGOYEN (2011; 2012); RAMÍREZ (2015).

6. En este trabajo entendemos el concepto "grupo vulnerable" como aquel colectivo limitado o excluido de la decisión política o en condición de desventaja frente a la mayoría o sectores hegemónicos. En este sentido, político, la exclusión excede lo demográfico -mayoría vs. minoría de la población-. Asimismo, esta noción de la "vulnerabilidad", en términos de desequilibrio de poder o derechamente de dominación, no se opone a la idea de "minoría" o "grupo minoritario", cuando se plantea este concepto desde la perspectiva política descrita. Ergo, puede hablarse de grupos "vulnerables" o "minoritarios", sean o no una mayoría o minoría demográfica (MELLO, 2020; MELLO y LACERDA, 2020; MARIÑO, 2001, pp. 21-23).
} 
en la cultura jurídica, la cultura constitucional y el reconocimiento del derecho a la identidad cultural estos grupos históricamente excluidos en los países latinoamericanos ${ }^{7}$.

En este contexto nos preguntamos, primero, qué transformaciones o controversias se pueden identificar en la cultura jurídica chilena en relación a los nuevos marcos de reconocimiento de la identidad cultural. Segundo, en perspectiva metodológica, si es posible estudiar ordenamientos jurídicos tomando en cuenta solo el derecho legislado, sin considerar otros aspectos no positivos del campo jurídico, como las prácticas, las percepciones y preconcepciones de los sujetos que interactúan en este espacio social (particularmente, los jueces y sus sentencias).

Desde la perspectiva planteada, nuestra investigación: (i) busca estudiar las transformaciones y conflictos que se visualizan en la cultura jurídica chilena en relación al derecho a la identidad cultural (focalizado en pueblos indígenas y tribales); y para ello, (ii) formula una metodología adecuada para realizar la pesquisa indicada sobre la cultura jurídica y el derecho a la identidad cultural.

Al efecto, nuestra hipótesis metodológica será que para estudiar la cultura jurídica no basta considerar solo el derecho positivo, sino que se debe contemplar el campo jurídico en su conjunto y que es necesario tomar en cuenta el máximo de factores posibles de aquellos que inciden en la creación, transformación y aplicación del Derecho $^{8}$. En especial, que se requiere estudiar el contexto, la interacción de los textos normativos con las prácticas y comprensiones de sus operadores y cómo se reflejan en la jurisprudencia9.

Así, en este artículo: i) conceptualizamos la cultura jurídica; ii) explicamos brevemente el derecho fundamental a la identidad cultural conforme los estándares definidos por la Corte Interamericana de Derechos Humanos (Corte IDH); iii) exponemos el enfoque metodológico propuesto para el estudio de la cultura jurídica; iv) presentamos sintéticamente nuestro estudio aplicado; v) concluimos exponiendo los principales hallazgos de la investigación.

\section{La cultura jurídica, concepto y perspectivas}

Siguiendo a Friedman (1975), el sistema jurídico tiene tres componentes. El componente estructural, que corresponde a las instituciones jurídicas, la forma de organización y los procedimientos diseñados para el funcionamiento de dicho sistema: tipo de tribunales, división de poderes entre legisladores, gobernadores, jueces, jurados y

\section{FIGUEIREDO (2019) pp. 728-732; FAUNDES y LE BONNIEC (2020).}

8. Ya veremos desde NELKEN (2017) que, al mismo tiempo, se requiere delimitar la cultura jurídica como objeto de estudio para procurar "contener" su amplitud y viabilizar la investigación.

9. LÓPEZ MEDINA (2015) p. 231. 
oficiales administrativos; y los procedimientos respectivos en esas instituciones. El elemento sustantivo, compuesto por las normas jurídicas vigentes y su operación concreta y efectiva en la vida social. El componente cultural, configurado por el conjunto de los valores y actitudes vinculados al Derecho. Luego propone sus conocidas categorías de la "cultura jurídica “interna" y la "cultura jurídica externa"10. La cultura jurídica externa refiere al "conjunto de las ideas, valores, opiniones, expectativas y creencias que las personas en sociedad mantienen frente al sistema jurídico y sus diversos componentes"; la cultura jurídica externa se compone de los entendimientos, acciones y orientaciones que prevalecen en las personas de una sociedad respecto del Derecho y su sistema legal ${ }^{11}$.

La cultura jurídica interna, específicamente, es la internalizada por los "operadores jurídicos" o "actores jurídicos", aquellos miembros de la sociedad que realizan actividades propias del sistema jurídico, en razón de las profesiones u oficios que practican. Comprende el derecho positivo a través de las prácticas aplicadas por ellos, sus comprensiones del Derecho y sus formas de relación directa y preponderantes con las estructuras e instituciones jurídicas. Asimismo, sus valores, creencias, ideas, actitudes, prejuicios, orientaciones, modos de pensar y de sentir, formas de expresarse y de argumentar; sus prácticas y hábitos de trabajo ${ }^{12}$. Es decir, la cultura jurídica interna corresponde al desempeño profesional de los abogados y abogadas, sean jueces, juezas, notarios u otros funcionarios/as de la administración de justicia, litigantes y docentes de Derecho, todos/as con educación jurídica formal en Derecho ${ }^{13}$.

López Medina señala tres dimensiones que componen la cultura jurídica (interna): i) "una teoría del lenguaje", diferenciando disposición (texto legal) y norma (significado del enunciado legal); ii) "una teoría de la interpretación", como "atribución de un significado normativo a una disposición”, mediante un proceso hermenéutico en el que el significado jurídico es una variable determinada por las valoraciones y decisiones del intérprete, de los operadores jurídicos en particular, sobre los enunciados normativos concretos; (iii) una teoría del Derecho que, armónicamente con las dimensiones anteriores, entiende al Derecho como actividad doctrinal y jurisprudencial, por sobre la legislación en sí. Desde este enfoque, el Derecho es mucho más que "la Ley" (como conjunto de enunciados normativos del Poder legislativo), sino

10. FRIEDMAN (1975) p. 223.

11. SQUELLA (1988) p. 31.

12. LÓPEZ MEDINA (2015) p. 233; TARELLO (1988) p. 24; SQUELLA (1988) p. 537; PAILLACURA (2019).

13. FUENZALIDA (2000) p. 473. 
que comprende el conjunto de normas que los intérpretes extraen de las leyes y sus enunciados formales ${ }^{14}$.

Con todo, más allá de los preceptos clásicos que reseñamos, entendemos la cultura jurídica de forma porosa, articulada, comunicada con los demás componentes extrajurídicos. Así, el "Derecho" como objeto en estudio corresponde a un escenario dinámico, inclusivo de la cultura y del campo jurídico en que ella se despliega, lo que lleva a comprender el "Derecho" de forma contextual, producto de procesos sociohistóricos, con influencias recíprocas entre los niveles local, nacional, regional y global, en interrelación y transformación permanente de sus componentes ${ }^{15}$.

En el sentido descrito, la cultura jurídica es una dimensión de "la cultura" de una sociedad o de una parte de ella, comparte su amplitud, complejidad y la frecuente problematización de su propio concepto. Luego, para delimitar los alcances, a lo menos en este trabajo, -siguiendo a Salas- la cultura, corresponde a "una trama de sentidos y significados transmitidos por símbolos, mitos, dichos, relatos, prácticas y reconstrucciones que expresan una comprensión y reconstrucción del sentido de la totalidad de la existencia y de los sujetos entre sî" ${ }^{16}$. No se trata de una caracterización estancada, sino de una dinámica en permanente interacción y cambio que, al mismo tiempo, presenta núcleos de sentido, lazos y congruencias que permiten su afirmación como una "unidad", pero nunca cerrada, sino que "permeable" y descentrada ${ }^{17}$. Ergo, en tanto objeto de investigación, para estudiar una determinada "cultura jurídica”, será necesario, a su vez, delimitar, operativamente, a lo menos, en qué sentido, en qué niveles, en qué dimensiones de la cultura y la cultura jurídica propiamente tal, será realizada la pesquisa ${ }^{18}$.

Consecuentemente, para efectos de nuestro estudio, si bien hablaremos de "la cultura jurídica chilena”, entendemos que es un concepto amplio -y a veces polisémico en la percepción de los propios operadores jurídicos-con múltiples miradas y comprensiones mediadas por los contextos, geografías, tiempo, historia, etc. y que se articula en diversos niveles (comunitario, local, nacional, regional, global). Pero, no obstante, consideramos que sí es posible levantar descripciones, más o menos precisas, a lo menos, comprensivas de las formas de comportarse, de cómo se toman decisiones, de sus influencias, en el comportamiento de jueces, fiscales y otros actores jurídicos.

14. LÓPEZ MEDINA (2015) p. 234.

15. Sobre la relación cultura y derecho, en perspectiva intercultural, de "Justicia en contexto" v. FAUNDES (2017); SALAS y FAUNDES (2018).

16. SALAS (2003) pp. 54-55.

17. v. Para una revisión extensa y crítica del concepto de cultura, del modelo de determinación estructural, funcional a los procesos de colonización y dominación v. FAUNDES (2020c); CLAROS y VIANA (2009); FORNET-BETANCOURT (2011).

18. NELKEN (2017) p. 339. 
En particular, porque la jurisprudencia es uno de los ámbitos en que se puede apreciar más claramente la cultura jurídica (interna) ${ }^{19}$. En este sentido, los procesos de toma de decisiones jurisdiccionales, al mismo tiempo, son espacios de producción y reconfiguración de identidades diferenciadas, de contraposición de intereses, de disputa de ideologías, de cálculos estratégicos, de tensiones e intereses marcados por los medios y la opinión pública, etc ${ }^{20}$. Todo ello, en su conjunto configura la "cultura jurídica".

\section{El derecho fundamental a la identidad cultural configurado por la Corte IDH}

El derecho a la identidad cultural se fundamenta en un conjunto de normas del Derecho Internacional de los Derechos Humanos que refieren a la tutela de minorías culturales $^{21}$. En este sentido se define como:

El derecho de las comunidades tradicionales y sus miembros a vivir de acuerdo con su cultura, y a ser reconocidos como diferentes en las relaciones con otros grupos. Comprende el derecho a conservar su propia cultura, espiritualidad y referentes cosmogónicos, su patrimonio cultural tangible o intangible, su memoria histórica y su identidad presente; el derecho a que se respeten y protejan sus conocimientos, lengua, creencias, artes, moral, religión, formas de justicia y organización ${ }^{22}$.

Se trata de un derecho de naturaleza colectiva, de titularidad de las propias comunidades indígenas y también de grupos tribales afrodescendientes en una doble dimensión: (i) que se respete, valore y proteja su identidad y cultura frente al Estado y a terceros, con todos los bienes materiales e inmateriales que los componen; (ii) que su universo existencial, sus comportamientos y sus derechos sean interpretados a la luz de tal identidad cultural ${ }^{23}$.

La Corte IDH viene sosteniendo que el derecho a la identidad cultural es un derecho de carácter fundamental y de naturaleza colectiva de pueblos y comunidades indígenas, que debe ser respetado en una sociedad multicultural, pluralista y democrática $^{24}$. Además, reciéntenme agregó que no solo se trata de un derecho de pueblos indígenas y tribales, sino que es un derecho de todas las personas y grupos, integrante

19. DE LA SIERRA (2004) pp. 77-78.

20. MELLO (2015).

21. v. FAUNDES (2019b). Sobre la comprensión seguida de la expresión "minoría” v. Nota 4.

22. FAUNDES (2019a) pp. 56-59.

23. MELLO y LACERDA (2020).

24. Pueblo Indígena Kichwa de Sarayaku vs. Ecuador (2012), p. 66, cons. 213; v. FAUNDES (2019b) p. 516. 
del derecho a "participar en la vida cultural", contenido en un gran número de instrumentos internacionales, de nivel regional americano y universal ${ }^{25}$. Con este alcance se amplía su potencial impacto normativo. En estos términos, el derecho a la identidad cultural funciona, al mismo tiempo, como un derecho matri $z^{26}$ y filtrohermenéutico ${ }^{27}$. Esto es, el derecho a la identidad cultural opera: (i) como un derecho sustantivo cuyo contenido debe garantizarse por el Estado; (ii) constituye una base de fundamentación y un núcleo que otorga significado a los demás derechos fundamentales de sus titulares; y (iii) genera un efecto que filtra ${ }^{28}$ todo el ordenamiento jurídico, por lo que todo otro derecho debe ser resignificado, reinterpretado o, al menos, contextualizado, en relación con la cultura del titular o titulares que ejerce o ejercen el derecho. El derecho fundamental a la identidad cultural implicará, entonces, tanto proteger manifestaciones identitarias y culturales de base, como, en especial, la obligación de comprender los comportamientos de cada sujeto o su comunidad a la luz de su visión del mundo, de los significados que tal comunidad da a sus comportamientos; y, no únicamente, desde los significados, representación o precomprensiones, de la cosmovisión de la cultura dominante. Constituye un imperativo para el intérprete judicial del derecho, que le exige desplazarse de su centro cognitivo y de representaciones, hacia la comprensión "del otro" y su cultura ${ }^{29}$. El derecho a la identidad cultural implica, entonces, revisar hermenéuticamente otras categorías de derechos fundamentales, tales como: el derecho de dominio, inclusivo de la propiedad indígena y el uso ancestral de la tierra; el derecho al acceso a la justicia y al debido proceso, en relación con el derecho a utilizar los propios sistemas de justicia indígena, al derecho propio o consuetudinario; y, en especial, el derecho a que la persecución penal integre la revisión de las conductas conforme los contextos culturales en que ocurrieron ${ }^{30}$, el derecho a la protección del medio ambiente, considerando los efectos intangibles -culturales- no perceptibles para los terceros no miembros de pueblos indígenas ${ }^{31}$; el derecho a la participación en la vida social y política, para que integre las formas pro-

25. Comunidades indígenas miembros de la asociación Lhaka Honhat (nuestra tierra) vs. Argentina (2020), pp. 85-86, infra. 238.

26. v. FAUNDES y RAMÍREZ (2020).

27. FAUNDES (2019b) p. 517; MELLO y FAUNDES (2020). Sobre el concepto de "filtro hermenéutico" v. SOUZA NETO y SARMENTO (2014) y sobre "eficacia irradiante" de los derechos fundamentales. v. “Caso Lüth” (1958) párr. 198.

28. SARMENTO (2010) pp. 64-75.

29. FAUNDES (2017) p. 52.

30. KALINSKY (2000) pp. 156-161; DE MAGLIE (2012) pp.193-237; FAUNDES (2019a) pp. 56-58. 31. CARMONA (2013) p. 83; FAUNDES (2020b) pp. 369-373 ; LÓPEZ Y MHOR (2014) pp. 108-115. 
pias de organización y participación tradicionales; y se reconozca la consulta indígena como un derecho autónomo y complejo, interdependiente, con los otros derechos de estos pueblos.

En el sentido anterior, ha dicho la Corte Interamericana que el derecho de las personas a disfrutar de su propia cultura guarda relación con los modos de vida estrechamente asociados al territorio y al uso de los recursos de los miembros de comunidades indígenas y las actividades tradicionales de subsistencia ${ }^{32}$; que "el derecho a la propiedad colectiva de los pueblos indígenas está vinculado con la protección y acceso a los recursos naturales que se encuentran en sus territorios"; que el bienestar físico, espiritual y cultural de estas comunidades y pueblos está estrechamente ligado con la protección del medio ambiente en que desarrollan sus vidas, todo lo cual, resulta "fundamental e inescindible para su supervivencia alimentaria y cultural"

Por último, en relación con el constitucionalismo latinoamericano, se ha afirmado que el derecho a la identidad cultural tiene el efecto potencial de transformar los diseños constitucionales de los países de la región, dado el impacto que genera en la cultura jurídica y la "cultura constitucional" ${ }^{34}$. Nosotros, a la luz de la presente investigación, revisaremos si el derecho a la identidad cultural puede constatarse como una nueva categoría ius fundamental, justificada en la norma constitucional e internalizada en la cultura jurídica de los actores jurídicos chilenos (conforme la jurisprudencia y sus propias percepciones).

\section{Enfoques metodológicos para el estudio de la cultura jurídica}

\subsection{Estudio de la cultura jurídica desde el enfoque jurídico clásico de la escuela de Friedman}

Como indicamos introductoriamente, nuestro objetivo es el estudio de las potenciales transformaciones en la cultura jurídica chilena, focalizada en la recepción del derecho a la identidad cultural de pueblos indígenas y otros grupos. Asimismo, hemos postulado que el análisis exclusivo del ordenamiento positivo resulta insuficiente. Por ello, presentamos a continuación una propuesta metodológica interdisciplinaria que nos permite comprender las dinámicas de creación, transformación y aplicación del Derecho, aplicable a personas indígenas, sus comunidades y pueblos, así como a otros grupos culturalmente identitarios y sus miembros -como los afrodescendientes-. Todos, en tanto destinatarios del Derecho, pero también como actores partícipes del Derecho.

32. Comunidad Indígena Sawhoyamaxa Vs. Paraguay (2006), parr. 98.

33. Comunidades indígenas miembros de la asociación Lhaka Honhat (nuestra tierra) vs. Argentina.

34. FIGUEIREDO (2019) pp. 733-734-751. 
Para el desarrollo de esta metodología el proceso de análisis se focaliza en los actores jurídicos, en ese sentido, en la "cultura jurídica interna", pero en interacción con el campo jurídico en general, con los factores extrajudiciales y, desde el punto de vista del derecho a la identidad cultural, siempre en relación a los destinatarios finales del Derecho.

Esta perspectiva metodológica supone que cuando los jueces resuelven "conforme a Derecho" (usando la expresión propia de la perspectiva positivista), hacen mucho más que aplicar silogísticamente los enunciados normativos positivos, sino que en la toma de decisiones de las cortes operan otros múltiples factores "extrajurídicos". Siems (2018) explica que "este enfoque es epistemológicamente más abierto" y releva la prevalencia de las narrativas locales, con un énfasis en la pluralidad, la intersubjetividad, la experiencia y el conocimiento situado, mediante la hermenéutica e hibridación. Señala, así, esta forma de estudiar la cultura jurídica rechaza el funcionalismo del Derecho ${ }^{35}$ y favorece la especificidad local, enfatizando el rol de la cultura, la pluralidad y la subjetividad. Consecuentemente, la cultura jurídica, tanto incluye las estructuras jurídicas formales, como excede las instituciones de elaboración de las leyes y aplicación del Derecho, porque emergen otras formas de creación del orden social lo que debe considerarse metodológicamente ${ }^{36}$.

Según se ha descrito, buscamos desarrollar una metodología interdisciplinaria, que traspasa la Ciencia Jurídica -en sentido ortodoxo-, en que, además de la hermenéutica jurídica, entre otras técnicas metodológicas, se integra la etnografía, el análisis de discurso y la semiología de las ciencias de la comunicación.

\subsection{Método y perspectiva crítica para el estudio de la cultura jurídica desde Da- vid Nelken ${ }^{37}$}

Nelken (2017) plantea que un enfoque metodológico centrado en la cultura jurídica y el examen de las interconexiones entre el Derecho, la sociedad y la cultura, interrelacionadas como "Derecho en acción" y "Derecho vivo", refiere al rol del Estado de Derecho en las sociedades. En consecuencia, que el concepto de cultura jurídica requiere operacionalizar el concepto de cultura y resolver los problemas que en cuan-

35. El método funcionalista incorpora la perspectiva de la teoría de sistemas en el derecho, en general propone la comprensión y explicación de las estructuras sociales a partir de las funciones de las estructuras sociales dentro de la sociedad y no desde su origen histórico, de las contextuales y temporales, un subsistema binario de lo jurídico y lo antijurídico. MONTORO (2007) pp. 365-369.

36. SIEMS (2018) pp. 116-148-149.

37. Si bien el autor formula sus críticas metodológicas en relación a la comparación de culturas jurídicas, su análisis de la cultura jurídica como objeto de estudio nos parece muy pertinente a nuestro propio esfuerzo propositivo metodológico. NELKEN (1997; 2017). 
to al método resultan de estos conceptos. En particular, critica a Friedman porque -señala- utilizó la noción de cultura con demasiada amplitud -"desde la cultura del individuo, hasta la de sociedades enteras" ${ }^{38}$. Al efecto, indica que Friedman concibe la cultura jurídica como una gran superposición de múltiples niveles de cultura que varían en contenido, alcance e influencia en su relación con las instituciones de los ordenamientos jurídicos estatales. Luego, advierte Nelken, que esa amplitud de niveles, unidades supranacionales y subnacionales, constituyen un objeto de estudio muy amplio y complejo que dificulta las investigaciones. Por ejemplo, aunque se ubique la cultura jurídica en un solo nivel (local, nacional o regional/continental), ella comprende una variedad de unidades diferentes, conectadas, todas en permanente cambio, en un contexto de interacción mutua con las demás. Además, estas unidades dan lugar a la vida social de variadas formas, por ejemplo: a través de memorias, tradiciones históricas, en tipos de prácticas, actitudes, expectativas y maneras de pensar, rutinas organizativas y de socialización profesional. Ante todo ello, para Nelken, (2017) el esfuerzo radicará en desarrollar una metodología que circunscriba suficientemente el objeto de investigación con la finalidad de viabilizar la pesquisa, asumiendo "las complejidades de la cultura jurídica vivida con su mezcla de elementos superpuestos y potencialmente competitivos" 39 . En este marco, sostiene que son tres los elementos que evidencian la coherencia que configura la cultura jurídica y partir de lo cual puede ser estudiada:

(1) cuando existe un vinculo intrínseco entre los elementos que componen la cultura jurídica;

(2) si la conexión existe en la medida en que los participantes hablen sobre este patrón o aspecto de la cultura jurídica como si existiese (exista o no); o

(3) en tanto el elemento articulador de la cultura jurídica sea impuesto por el investigador a través de procesos de categorización o la construcción de tipos ideales ${ }^{40}$.

Asimismo, el autor plantea algunas advertencias para los estudios desde estos encuadramientos:

i. Si bien la dirección del vínculo que configura la coherencia es principalmente de la cultura en general hacia la cultura jurídica en particular, pueden haber transformaciones en sentido inverso. Entonces, en este caso, la metodología debe ser capaz de dar cuenta de este doble sentido de interacción ${ }^{41}$. Si llevamos esta cuestión a la identidad cultural, podemos observar que existen fenómenos globales que amplían

38. NELKEN (2017) pp. 333-339.

39. NELKEN (2017) pp. 339-343.

40. NELKEN (2017) pp. 339-343.

41. NELKEN (2017) p. 345. 
los marcos culturales en relación con la diversidad, y, al mismo tiempo, el propio ejercicio del derecho a la identidad cultural, en lo local, va contornando y consolidando el Derecho en general.

ii. Explica que estas formas de identificar la coherencia que configura la cultura jurídica no son estáticas ni cerradas porque: (i) con frecuencia, los participantes piensan que están haciendo algo -lo realicen o no, tengan éxito o no-, ya que esto es lo que da sentido a sus acciones; (ii) o bien, al delimitar los objetos que constituirían la coherencia de la cultura jurídica, se puede estar categorizando desde la perspectiva del investigador, desde sus patrones prestablecidos y, con ello, imponiendo coherencia cultural. Por ello, advierte, tanto, en no suponer necesariamente que todas las transformaciones dicen relación con la cultura jurídica, porque los valores culturales son partes de múltiples causas de los eventos ${ }^{42}$; $\operatorname{como}$ de la importancia de evitar "las afirmaciones sobre la existencia de patrones culturales que luego ayudan a traerlos a la existencia" (efecto circular).

En consecuencia, observa la necesidad de realizar pesquisas descriptivas, más que el esfuerzo de demostrar pretendidas relaciones causales en relación a categorías hipotéticas que terminen imponiendo el resultado de la hipótesis. Y que, en este sentido, será relevante formular preguntas adecuadas para pesquisar qué cambió -si es que algo cambió- y no para demostrar una transformación preconcebida (en un sentido deseado o esperado por el investigador).

iii. Destaca la diferencia entre focalizar la investigación en un enfoque hermenéutico ("giro interpretativo"), versus una concepción positivista centrada en el comportamiento objetivo. Al efecto indica que el enfoque positivista buscaría comprender la cultura jurídica basado en la causalidad de variables e hipótesis postuladas, que explicarían los cambios de comportamiento jurídicamente relacionados. Mientras, el enfoque interpretativo solo indaga sentidos en base a las descripciones del Derecho como saber local y, más ampliamente, procura una hermenéutica centrada en identificar las ideas de justicia del sistema en su conjunto ${ }^{43}$.

Así, el presente estudio entiende el Derecho, ampliamente, como campo jurídico. Luego, usando las dimensiones que componen la cultura jurídica (interna) -según vimos desde López Medina-, presenta el contexto -el escenario sociopolítico e histórico- en que interactúan los actores jurídicos, revisa las principales disposiciones constitucionales pertinentes y luego muestra su interpretación por los tribunales con competencia constitucional (cortes de apelaciones, Corte Suprema y Tribunal Constitucional). Al efecto, se considera el significado jurídico como una variable determi-

42. NELKEN (2017) pp. 343-346.

43. NELKEN (2017) pp. 339-343. 
nada por las valoraciones y decisiones de los actores jurídicos en particular. También, recogiendo las prevenciones de Nelken (1997; 2017), estudia la cultura jurídica desde su composición compleja, dinámica y en interacción, pero acotando el campo jurídico como objeto de estudio; y, asimismo, para el abordaje indicado, la estrategia metodológica considera preguntas de investigación descriptivas y no inductivas.

\subsection{Metodologías para estudiar la cultura jurídica desde las ciencias sociales}

Nuestra investigación suma un enfoque socioantropológico, utilizando el marco analítico del campo social de Pierre Bourdieu (1991), aproximándose al Derecho en tanto se constituye como un campo jurídico. Tal perspectiva, centrada sobre los actores y sus prácticas, requiere una metodología que evidencie las relaciones objetivas y posiciones estructurales de los actores que componen el campo jurídico, y de esta forma observar cómo movilizan recursos, estrategias y capitales en su quehacer cotidiano, cuyos fines van más allá de hacer justicia. En particular, requiere entender cómo estas luchas se dan en el terreno de la cultura jurídica, sobre la legitimidad de decir, de definir e interpretar el Derecho. En palabras de Bruno Latour ${ }^{44}$, se trata de considerar el "derecho en acción", estudiarlo tal como se produce y no solo como se dice o afirma positivamente, lo que implica interesarse no solo en los actores y sus propiedades sociales, sino en cómo se van configurando las controversias jurídicas. Este enfoque praxeológico ${ }^{45}$, que va complementando el estudio del campo social, es central para abordar la emergencia del derecho a la identidad cultural y los razonamientos jurídicos asociados a este proceso, en función de sus diversos contextos de enunciación. En este marco, la cultura jurídica es un presupuesto central del sistema de creencias o reglas del juego, el illusio, en cual se mueven los propios agentes jurídicos, que van condicionando sus maneras de ser y pensar, su habitus, develando el campo jurídico ${ }^{46}$. El estudio de estas transformaciones evidencia la evolución de las prácticas, discursos y razonamientos jurídicos implícitos en los usos de las normas.

Así, desde esta perspectiva, la propuesta metodológica procura superar la dicotomía entre el enfoque internalista y el externalista, para abordar la cuestión de la interrelación entre campos sociales y jurídicos ${ }^{47}$.

44. LATOUR (2002).

45. DUPRET (2010).

46. BOURDIEU (1991) pp. 95-99.

47. Diversos enfoques de las ciencias sociales tratan de desvelar la dimensión social del Derecho sea en término de "actividad social" v. DEWEY (2011), de "un sistema social autopoiético" v. LUHMANN (2002), o de una “cadena de producción o traducción” v. LATOUR (2002). 
En consecuencia, si bien el estudio de la jurisprudencia de alcance constitucional es muy importante, resulta insuficiente para evidenciar las eventuales transformaciones en el campo jurídico, considerando su contexto, interacciones, operadores, etc., ya que las decisiones judiciales difícilmente reflejan los factores extrajurídicos que determinan esas decisiones. Asimismo, las consideraciones de los precedentes no siempre logran expresar o restituir todas las dinámicas de un proceso de toma de decisión judicial, no contemplan el cumplimiento o incumplimiento de las sentencias o bien no son un medio adecuado para medir cómo la formación jurídica de los jueces ha incidido en sus decisiones ${ }^{48}$. En este sentido, como los fallos son producto del razonamiento jurídico de los sentenciadores y muchas veces obedecen a los acuerdos estratégicos adoptados entre ellos, tampoco representan, necesariamente, una muestra significativa de los conflictos o posiciones jurídico-sociales efectivamente presentados ante las cortes, ni de cómo esas cuestiones están operando en el campo social $^{49}$. Por ello, para lograr una aprehensión más amplia del contexto asociado a la decisión jurisdiccional, el método aplicado al estudio incluye la observación etnográfica y las entrevistas a los actores del sistema jurídico, en acción, para poder pesquisar las potenciales transformaciones que el derecho a la identidad cultural pudiesen estar provocando en la cultura jurídica chilena.

\subsection{La etnografía aplicada al estudio de la cultura jurídica chilena}

Nuestro objetivo, bajo esta perspectiva metodológica, es visualizar las transformaciones del campo jurídico y la cultura jurídica a partir de la interacción entre los diversos actores jurídicos que van delineando y aplican el derecho fundamental a la identidad cultural. Al efecto, la propuesta de metodología aplicada busca, en particular, alcanzar: (i) una descripción de la cultura jurídica desde la comprensión de los operadores del respectivo campo jurídico; (ii) una descripción desde los actores del campo jurídico, de cómo esa cultura jurídica ha recepcionado el derecho a la identidad cultural. Así se pesquisó cómo los actores del campo jurídico visualizan: las estructuras e instituciones, los valores culturales, hábitos, ideologías, intereses, prejuicios y discursos preponderantes que promueven, en relación con el derecho a la identidad cultural en el campo jurídico chileno.

48. DE LA SIERRA (2004) pp. 74-77.

49. Sobre comportamiento estratégico y factores extrajurídicos de las decisiones judiciales v. MELLO $(2015,2019 a)$. 
Teóricamente, la propuesta metodológica utiliza herramientas de la denominada "etnografía del Estado" que considera al Estado como una formación cultural y moral de sus agentes, sus instituciones, sus representaciones y producciones jurídicas en vía de transformación multicultural ${ }^{50}$. Asimismo, se considera el "Derecho" como un objeto antropológico (la cultura jurídica) y sociológico (campo jurídico), el cual es generador de orden, rutinas y de discurso social mediante la movilización de textos y corpus.

En lo estratégico, se realizó una investigación aplicada, piloto, mediante la cual se modeló la metodología mientras se iba realizando el estudio. La investigación empírica se realizó entre 2016 y 2019, estudiando las transformaciones del campo jurídico y la cultura jurídica chilena, desde la perspectiva del derecho a la identidad cultural, conforme las vivencias en el campo jurídico (penal) de integrantes del Pueblo Mapuche $^{51}$. El objeto de estudio etnográfico se centró en tribunales penales de las regiones de La Araucanía, del Bío Bío y de Los Ríos.

Se realizaron 35 entrevistas semiestructuradas a actores jurídicos: ministros de cortes, jueces, fiscales, defensores públicos y particulares ${ }^{52}$, a partir de las cuales, por una parte, se reconstruyeron sus trayectorias de vida y, por otra, sus conocimientos y saberes en relación con sus quehaceres cotidianos de juzgar, defender o acusar en contexto de diversidad cultural.

50. BOLADOS y BOCCARA (2014) p. 74.

51. El Pueblo Mapuche se ubica territorialmente en las regiones chilenas del Bío Bío, de Los Ríos, en la Metropolitana (Santiago) y, principalmente en la IX Región "de la Araucanía”, donde se focalizó nuestro estudio. Además, existe presencia mapuche minoritaria binacional en los sectores limítrofes de Chile con Argentina en la misma latitud de la Araucanía.

La distribución de la población indígena chilena es de 2.185 .792 habitantes a 2017 y su composición es heterogénea de nueve pueblos indígenas reconocidos. A 2017 el Pueblo Mapuche es el pueblo indígena con mayor población del país con 1.745 .147 que corresponde a un 9,9\% de la población chilena (de un total de 17.574.003 de habitantes). La población mapuche, a su vez, constituye el 79\% del total nacional de personas que se declaran indígenas. EL 11\% de los mapuche viven en la Región del Bío Bío y el 37\% en La Araucanía. INE (2018). Síntesis de resultados Censo 2017. INE y MIDEPLAN (2005). Estadísticas sociales de los pueblos indígenas en Chile. Censo 2002. Cruce de datos propio.

52. Se seleccionaron los entrevistados en relación a las distintas instituciones que componen el campo jurídico chileno: el Ministerio Público, el Poder Judicial, las Cortes de Apelaciones, la Defensoría Penal Pública, el Centro de Investigación y Defensa Sur (CIDSUR), Asociación Nacional de Magistrados (ANM). Se logró la entrevista a un ministro de la Corte Suprema a cargo de políticas de acceso a la justicia de poblaciones vulnerables. 
Las preguntas de base de la entrevista semiestructurada fueron: ¿qué entiende Ud. por cultura jurídica? ¿Qué entiende usted por identidad cultural?; ¿identifica el derecho a la identidad cultural en la cultura jurídica chilena?; y, si la última respuesta fue afirmativa, se consultó: ¿qué interacciones visualiza entre la cultura jurídica y el derecho a la identidad cultural? La entrevista también contó con preguntas dirigidas a arrojar un perfil personal del operador y a caracterizar su área de desempeño; también se usaron preguntas adicionales para recoger otros aspectos que pudieran ser significativos en la cultura jurídica y su interconexión con el derecho a la identidad cultural $^{53}$. Estas entrevistas también permitieron recolectar información acerca de sus características sociales, su trayectoria, su quehacer, su posición ante la diversidad cultural en los tribunales y su percepción de la transformación del Derecho, además de su reflexión sobre sus propias prácticas.

La estrategia metodológica también consideró: observación etnográfica en tribunales $^{54}$, 4 mesas redondas con actores jurídicos (del poder judicial, defensorías, fiscalías y abogados particulares) ${ }^{55}$, análisis semiodiscursivo de medios de prensa y sentencias $^{56}$, articulándolo con las observaciones etnográficas en tribunales.

53. Las preguntas secundarias indicadas fueron las siguientes: ¿qué considera caracteriza la cultura jurídica de un determinado campo jurídico?, de acuerdo a cómo comprende la idea de cultura jurídica ¿qué actitudes o comportamiento considera caracterizan a los operadores del campo chileno?; ¿existe un derecho a la identidad cultural?, si estima que existe ¿quiénes serían titulares de ese derecho?, ¿es un derecho fundamental?; ¿cree que la identidad cultural de los pueblos indígenas de es recogida, valorada y respetada en la cultura jurídica chilena?

54. Se priorizó la observación etnográfica como método de recolección de datos empíricos, lo que permitió acercarse a las rutinas de las audiencias, las prácticas de los actores jurídicos y sus interacciones con usuarios mapuche. Constituyó también un elemento central en la triangulación y discusión de las fuentes escritas y orales obtenidas por las otras técnicas. Sobre recientes estudios que han recurrido a la etnografía judicial en Chile v. AZÓCAR (2018); GONZÁLEZ (2018); HERSANT (2019); MIRANDA y GAC (2020).

55. Para las mesas redondas se usó la técnica del "grupo de discusión" CANALES (2006). Se desarrollaron mesas redondas en dos cortes de apelaciones (Valdivia y Concepción). Se trató de mesas redondas internas, cerradas, que reunieron a distintos actores del campo jurídico con los investigadores del proyecto y otros invitados de las universidades locales que facilitaron sus espacios.

56. El análisis semiodiscursivo está aplicado en este estudio para observar y entender el derecho en acción a partir, no solamente del lenguaje usado durante las audiencias, sino que integrar las lógicas internas (métodos) del razonamiento práctico de los actores jurídicos. CHARAUDEAU (2006); DUPRET (2006). 
El estudio del comportamiento de los actores jurídicos consideró dos enfoques:

i) Desde sus prácticas: la forma de dirigirse e interactuar entre agentes jurídicos especializados y las personas indígenas (mapuche); y la manera de aludir a aspectos socioculturales e integrarlos en su razonamiento jurídico, sea de forma oral o escrita. Y, en los casos de etnografía en tribunales, se observó si había presencia de autoridades tradicionales, si se usaba la vestimenta tradicional o si se recurría al mapudungun y al facilitador intercultural.

ii) Discursivamente: se prestó atención particularmente a los argumentos normativos esgrimidos por cada parte, observando, por ejemplo, si se mencionaba el Convenio 169 de la OIT y de qué forma, si solo se refería o si se argumentaba en base a dicho instrumento; o si se presentaban peritajes antropológicos.

La descripción histórico contextual del campo jurídico y de la cultura jurídica chilena fue complementada y cotejada con información de fuentes secundarias, principalmente bibliográficas.

Toda esta estrategia metodológica compleja permitió esbozar una cartografía del campo jurídico en relación con el discurso y percepciones de la interacción de la identidad cultural en la cultura jurídica.

Por último, es relevante prevenir que nuestra investigación, si bien considera entrevistas a actores jurídicos de diversos ámbitos jurisdiccionales, se focalizó en quienes se desempeñan principalmente en la competencia penal, en las regiones de mayor presencia de población indígena mapuche de Chile. No obstante, se trató solo de una opción metodológica, para establecer un aspecto del campo jurídico delimitado que facilitara el estudio y optimizara los recursos. En particular, porque la jurisdicción penal es un espacio favorable para mostrar, mediante el comportamiento judicial, los referentes culturales más arraigados en la sociedad. Pero la delimitación metodológica indicada no impide el estudio de la cultura jurídica en contextos normativos de otras competencias judiciales en sentido material (constitucional, ambiental, familia, entre otras) y en diversos niveles jurisdiccionales (nacionales, comparados o internacionales). Por el contrario, esfuerzos metodológicos como el que aquí presentamos constituyen una oportunidad para el desarrollo de otras investigaciones en otros ámbitos del campo jurídico chileno, la cultura jurídica y sus respectivas transformaciones en Chile ${ }^{57}$.

57. En perspectiva comparada v. FAUNDES y LE BONNIEC (2020). 


\section{La cultura jurídica chilena y el derecho a la identidad cultural: investigación aplicada en Chile}

Conforme hemos descrito precedentemente, la investigación se realiza en el nivel nacional o del campo jurídico chileno, con especificidad local respecto del campo jurídico de las regiones de La Araucanía, Bío Bío y Los Ríos, desde cuatro dimensiones: (1) el contexto histórico, social y político; focalizado en pueblos indígenas y el Pueblo Mapuche en particular; (2) el texto de la Constitución en relación al derecho a la identidad cultural; (3) la interpretación de ese texto dada por los tribunales en algunos precedentes destacados de alcance constitucional; (4) Estudio socio-etnográfico de la cultura jurídica chilena y el derecho a la identidad cultural.

La segunda y tercera dimensión se consideran como base positiva o normativa (en un enfoque jurídico hermenéutico, según se describió), para en el cuarto caso estudiar la cultura jurídica de los actores jurídicos, propiamente tal (cultura jurídica interna), desde una perspectiva antropológica etnográfica. En todas las dimensiones el elemento articulador es el derecho fundamental a la identidad cultural.

\subsection{Campo jurídico chileno, el contexto histórico, social y político en relación al derecho a la identidad cultural}

Las interacciones del campo jurídico chileno se vinculan, por una parte, con instrumentos internacionales en materia de derechos humanos, universales y regionales, particularmente aquellos que reconocen derechos de naturaleza cultural ${ }^{8}$. Conjuntamente, con la jurisprudencia de la Corte IDH en estas materias. También, con diversas reformas legislativas en el ámbito nacional que evidencian un proceso progresivo de reconocimiento de derechos a los pueblos indígenas y otros grupos vulnerables (no exento de debates y conflictos) ${ }^{59}$.

En el plano comparado e internacional regional la Convención Americana de Derechos Humanos $(\mathrm{CADH})$ y la jurisprudencia desarrollada por la Corte IDH, han tenido una sostenida influencia. La interacción de todas estas fuentes ha dado lugar a la conformación jurisprudencial de que se ha denominado corpus iuris de derechos

58. Entre otros, v. "Convención para la salvaguardia del patrimonio cultural inmaterial" (PARIS, 2003). Protege "el patrimonio cultural inmaterial (art. 1.a) ... de las comunidades, grupos e individuos..." (1.b); señala que el "patrimonio cultural inmaterial" comprende, entre otros: las (2.a) "tradiciones y expresiones orales, incluido el idioma", (2.c) los "usos sociales, rituales y actos festivos; los (2.d) "conocimientos y usos relacionados con la naturaleza y el universo; y las (2.e) "técnicas artesanales tradicionales".

59. Sobre "grupos vulnerables" ver Nota 4. 
humanos latinoamericano ${ }^{60}$, con un desarrollo en particular respecto de derechos de los pueblos indígenas ${ }^{61} \mathrm{y}$ otros grupos de matriz afrodescendiente ${ }^{62}$, los cuales coinciden en una centralidad sobre la mejor protección de la persona ${ }^{63}$.

Paralelamente, también se vienen planteando nuevas comprensiones del Derecho que superan la visión estadocéntrica y poco disponible a la interacción del Derecho Internacional de los Derechos Humanos con los ordenamientos internos, que introducen una nueva concepción interconectada -nacional, regional y globalmente- de los derechos humanos que supone, a lo menos, el diálogo entre los tribunales regionales de derechos humanos y las cortes nacionales ${ }^{64}$. Y, en armonía con esta corriente, el ordenamiento constitucional chileno manifiesta una apertura a la incorporación del Derecho Internacional de los derechos humanos, bajo lo que Mariela Morales llama una la "estatalidad abierta"65.

Asimismo, en el ámbito regional latinoamericano se constata el avance emergente de una nueva comprensión constitucional del Estado y de sus instituciones, denominada una "nueva matriz constitucional"66 o la "matriz democrática intercultural"67, comprensiva de la diversidad cultural y del derecho fundamental a la identidad cultural $^{68}$. No se trata solo de cambios normativos, sino de una abundante producción académica que ha venido sistematizando los cambios y muchas de las veces también proponiendo los marcos posibles o necesarios de implementar desde estas nuevas vi-

60. v. BOGDANDY et al. (2017).

61. v. AYLWIN et al. (2013); AGUILAR (2010) pp. 3-84; FAUNDES y VALLEJOS (2020).

62. v.: Aloeboetoe y otros vs. Surinam (1993), Comunidad Moiwana vs. Suriname (2005), Pueblo Saramaka vs. Surinam (2007), Comunidad Garifuna de Punta Piedra y sus miembros Vs. Honduras (2015).

63. v. NOGUEIRA y AGUILAR (2017).

64. v. BOGDANDY et al. (2017), BUSTOS (2012) p. 33; BUSTOS (2005); GARCÍA ROCA et al. (2015); MELLO (2019b) pp. 271-272; MELLO y FAUNDES (2020); PIZZOLO (2017).

65. MORALES ANTONIAZZI (2016) pp. 53-74.

66. RAMÍREZ (2015).

67. FAUNDES (2019b) pp. 521; SALAS y FAUNDES (2018).

68. FIGUEIREDO (2019) pp. 731-732; YRIGOYEN (2011). 
siones del constitucionalismo. Son miradas doctrinarias de amplia influencia judicial concreta $^{69}$.

En el ámbito interno, el retorno a la democracia en 1990 marcó el inicio de un nuevo ciclo reivindicativo indígena (enmarcado en un movimiento indígena americano más amplio reforzado a partir de los 500 años de la Conquista europea en América, cuyo hito detonante es el movimiento chiapaneco en México $^{70}$ ). Así, en Chile ya en 1989 las organizaciones indígenas del país negociaban una agenda de reformas con el futuro presidente de Chile ${ }^{71}$ y en 1992 diversas organizaciones mapuche planteaban un conjunto de demandas de derechos. En este contexto, en 1993 se dictaba la Ley Indígena $\mathrm{N}^{\circ} 19.253$ que constituye el primer marco de reconocimiento de derechos a los pueblos indígenas de Chile tras la recuperación democrática ${ }^{72}$. Sin embargo, por una parte, dicha ley solo refiere a las "etnias indígenas de Chile" y no a "pueblos indígenas"73. Al respecto, si bien en sentido antropológico los conceptos de pueblos y etnias son equivalentes, en términos jurídicos los instrumentos internacionales de derechos humanos refieren a los "pueblos indígenas" como sujetos de derechos.

69. Son muchos los estudios que abordan la transformación de la justicia y del Derecho en América Latina. Se interesan tanto en las reformas de sus instituciones (PÁSARA, 2007), como en las transformaciones de sus actores (BINDER, 2005), en la apertura hacia la interlegalidad (SANTOS, 1995) o el pluralismo jurídico en relación con los derechos de los pueblos indígenas v. YRIGOYEN (2012); SIEDER (2011) y con las nuevas visiones del constitucionalismo y los diseños constitucionales en perspectiva plurinacional o intercultural v. RAMÍREZ (2010); MELLO (2019b); FAUNDES (2019b). 70. BENGOA (2000a).

71. En el "Acuerdo de Nueva Imperial" el entonces candidato a la presidencia y más tarde presidente de Chile, Patricio Aylwin, compromete con los representantes indígenas de las organizaciones indígenas de todo el país las bases de lo que será la futura política e institucionalidad para los pueblos indígenas de Chile.

72. Referimos a la Ley Indígena 19253 como un hito político normativo en esta nueva etapa postdictadura. Aunque el desarrollo legislativo histórico chileno en materia indígena extenso escapa al objeto de este trabajo, cabe tener presente que a lo largo del siglo XX se dictó una extensa legislación, que se ha calificado, según la etapa y los fines de la misma, entre otras, como "asimilacionista" "proteccionista" e "indigenista". En ese marco, la ley que se considera antecesora de la actual ley Indígena 19.253, fue la Ley 17.729 de 1972. En la materia, entre muchos v. AYLWIN et al. (2013); BENGOA (2000b, 2007); VALENZUELA y OLIVA (2018).

73. "El Estado reconoce como principales etnias indígenas de Chile a: la Mapuche, Aimara, Rapa Nui o Pascuenses, la de las comunidades Atacameñas, Quechuas, Collas y Diaguita del norte del país, las comunidades Kawashkar o Alacalufe y Yámana o Yagán de los canales australes..." (art. 1, inc. $2^{\circ}$, Ley 19.253). 
También, en perspectiva política, es en la calidad de “pueblos indígenas", preexistentes al Estado, que estos grupos reclaman su libre determinación. Por un conjunto de razones jurídicas y políticas -incluidas las precedentes-, la Ley Indígena 19.253 fue objeto de muchas críticas y en 1997 comienza un proceso sostenido de demandas indígenas, de presión social y política por reconocimiento de derechos a la luz de los avances internacionales. Esta agenda social indígena fue abordada mediante diversas políticas gubernamentales, tales como el "Nuevo Trato" (2003) y el "Pacto Social por la Multiculturalidad" (2008), en cuyo contexto se aprobó la DNUDPI y el Convenio 169 de la OIT. Tras la entrada en vigencia del Convenio $\mathrm{N}^{\circ} 169$ de la OIT, que tiene el carácter de un tratado internacional de derechos humanos, según ha sido afirmado mayoritariamente por la jurisprudencia -según se verá más adelante- el tratamiento jurídicamente procedente es el de "pueblos indígenas". Pero la revisión jurisprudencial mostrará que el uso de la expresión "etnias" sigue siendo relevante.

De esta forma, el campo jurídico chileno en relación con las trasformaciones normativas vinculadas a los derechos humanos evidencia lo que podemos describir como un "doble flujo normativo" o tensión normativa en que, por una parte, la apertura constitucional y los nuevos instrumentos internacionales aprobados por el país generan una fuerza inductora hacia la transformación del campo jurídico, con el reconocimiento y ampliación de diversas categorías de derechos humanos y de derechos de los pueblos indígenas en particular. Pero, por otra, en un "flujo opuesto", en el mismo campo jurídico nacional, sigue imperando de forma hegemónica un derecho "monista-positivista" que resiste a las transformaciones. Pero, con todo, la lógica dominante muestra diversas "fisuras" o cambios ${ }^{74}$.

Este fenómeno -que parece paradójico-se aprecia respecto de diversos grupos vulnerables, como en el icónico "Caso Atala" en relación a la identidad de género ${ }^{75}$; o bien, en nuestro ámbito de estudio, con la condena en el llamado "Caso Lonkos", relativo a la vulneración de derechos de líderes y autoridades tradicionales mapuche ${ }^{76}$. Pero, en estos casos, tras las condenas, receptivamente, los gobiernos chilenos han realizado esfuerzos para el cumplimiento de las decisiones de la Corte IDH, tanto en relación con los casos en concreto, como con la adecuación normativa general.

Por su parte, los jueces en las diversas competencias y niveles jurisdiccionales, han venido dando respuesta a las demandas indígenas (en un amplio abanico de intensidades). Así, el proceso de reconocimiento de derechos que se observa es complejo, ya

74. AYLWIN et al. (2013); FAUNDES (2020c).

75. Atala Riffo y Niñas vs. Chile (2012).

76. Norín Catriman y otros... vs. Chile (2019); Corte Suprema (16.05. 2019). 
que se encuentra cruzado por disputas y recurrentes críticas hacia el aparato judicial por el apoyo -explícito o implícito- a las lógicas privadas inversoras ${ }^{77}$.

Se critica la visión formalista que sigue imperando en sus actores ${ }^{78}$. Pero, al mismo tiempo, pese a la resistencia anterior y de la ausencia de un marco constitucional de reconocimiento expreso de derechos de los pueblos indígenas, diversos fallos, han venido reconociendo los derechos de los pueblos indígenas, en particular en relación a su identidad cultural 79 . Todo ello sugiere una permeabilidad emergente del monoculturalismo jurídico chileno ${ }^{80}$.

Por ejemplo -según veremos en el apartado de jurisprudencia-, encontramos un desarrollo jurisprudencial importante en materia de propiedad, cruzado por conflictos entre particulares con propiedad inscrita y personas o comunidades indígenas reclaman sus derechos dada la ocupación histórica de estas tierras. También hay disputas respecto de la consulta indígena y los proyectos de inversión con efectos ambientales en territorios indígenas; o bien, en el ámbito de la administración de justicia, se discute en torno al derecho a la resolución de conflictos conforme las formas tradicionales indígenas, la valoración del derecho propio indígena; conjuntamente se han posicionado en mayor número las estrategias defensa penal que invocan argumentos culturales ${ }^{81}$ y consideran la intervención de peritos antropólogos, con la colaboración de facilitadores interculturales o, incluso, la intervención personal -como expertosde autoridades tradicionales indígenas en audiencias ${ }^{82}$.

Muchos de los debates enunciados han ocurrido en paralelo a la llamada "Reforma a la Justicia" ${ }^{3}$, en especial en el campo penal ("Reforma Procesal Penal" operada de 2000 en adelante en la Región de la Araucanía ${ }^{84}$ ) y han producido efectos en diversas materias de derechos humanos y de derechos de los pueblos indígenas, lo que ha motivado diversas críticas al sistema ${ }^{85}$.

77. AGUAS y NAHUELPAN (2018); MILLAMÁN (2019); POU (2011) p. 235.

78. COUSO y HILBINK (2011).

79. Esta fase de reconocimiento jurisprudencial emergente está más bien localizada en las regiones de mayor concentración indígena (En el norte, Aymara y Quechua, y en la macro región sur, Mapuche).

80. LE BONNIEC (2018b).

81. COUSO (2013); LE BONNIEC (2018a) p. 141; FAUNDES (2019a).

82. BERHO et al. (2018).

83. SOUSA (2007).

84. CEJA (2015); FAUNDES (2020c).

85. CLOUD y LE BONNIEC (2019) p. 250; FAUNDES (2013). 
Con todo, en el doble flujo referido, se advierten múltiples esfuerzos de los órganos judiciales que apuntan a mejorar los estándares de acceso a la justicia en materia intercultural. Por ejemplo: la suscripción a las Reglas de Brasilia sobre Acceso a la Justicia de las Personas en condición de Vulnerabilidad"(2008) ${ }^{86}$; la adscripción al "Protocolo Iberoamericano de actuación judicial para mejorar el acceso a la justicia de personas, comunidades y pueblos indígenas" (2014) por la Corte Suprema ${ }^{87}$ que derivó en la publicación por parte del Poder Judicial de un protocolo de acceso a la justicia de grupos vulnerables en marzo de 2020; o la adhesión de la Asociación Nacional de Magistrados a un protocolo de atención a usuarios y usuarias mapuche en los tribunales y juzgados de la Macrorregión Sur (Pau-Mapu) ${ }^{88}$.

Así, por una parte, en las últimas décadas en Chile se puede observar una resistencia política a realizar reformas constitucionales de reconocimiento de los pueblos indígenas y sus derechos ${ }^{89}$. Pero, al mismo tiempo, se aprecia una apertura relativa de los poderes ejecutivos y legislativos a introducir diversas reformas en el ámbito legal o al desarrollo de políticas públicas interculturales ${ }^{90}$. Mientras, la judicatura no logra producir una jurisprudencia robusta en torno a los derechos indígenas ${ }^{91}$.

Estos fenómenos de reconocimiento y resistencias muestran un campo jurídico chileno con un abanico de actores relevantes que interactúan con prácticas, comprensiones y representaciones, a veces en colaboración y otras en conflicto, en relación al derecho a la identidad cultural, todo lo cual ha sido objeto del estudio aplicado que se expone en los próximos apartados.

86. v. RIBOTTA (2012).

87. La Corte Suprema, como miembro de la XVII Cumbre Judicial Iberoamericana desarrollada en el año 2014 en Santiago de Chile, ha suscrito el Protocolo iberoamericano de actuación judicial para mejorar el acceso a la justicia de personas, comunidades y pueblos indígenas.

88. Prensa UC Temuco» Asociación de Magistrados aprueba protocolo de atención elaborado por la UC Temuco. Disponible en: https://prensa.uct.cl/2019/10/asociacion-de-magistrados-apruebaprotocolo-de-atencion-elaborado-por-la-uc-temuco.

89. RODRÍGUEZ (2011).

90. v. Política de Educación Intercultural”. Disponible en: https://escolar.mineduc.cl/inclusionconvivencia-e-interculturalidad/politica-educacion-intercultural/. "Programa de educación intercultural bilingüe". Disponible en: http://peib.mineduc.cl/wp-content/uploads/2018/05/20180226PEIB-2010-2016-Versi\%C3\%B3n-Final.pdf.

91. CLOUD y LE BONNIEC (2012). 


\subsection{La Constitución y el derecho fundamental a la identidad cultural}

\section{Constitución Política de la República (CPR)}

En el caso chileno no existe una disposición constitucional de reconocimiento de los pueblos indígenas, ni de otros grupos minoritarios ${ }^{92}$. Con todo, el reconocimiento sí se puede sostener a partir de la interpretación de la CPR de acuerdo a la jurisprudencia -como veremos-. Para esos efectos se deben destacar los siguientes artículos de la Constitución:

Artículo 1:

"Las personas nacen libres e iguales en dignidad y derechos [...]

El Estado está al servicio de la persona humana y su finalidad es promover el bien común, para lo cual debe contribuir a crear las condiciones sociales que permitan a todos y a cada uno de los integrantes de la comunidad nacional su mayor realización espiritual y material posible, con pleno respeto a los derechos y garantías que esta Constitución establece.

Es deber del Estado..., promover la integración armónica de todos los sectores de la Nación y asegurar el derecho de las personas a participar con igualdad de oportunidades en la vida nacional".

Artículo 19:

La Constitución asegura a todas las personas: $\left(2^{\circ}\right)$ "La igualdad ante la ley...";

$\left(3^{\circ}\right)$ "La igual protección de la ley en el ejercicio de sus derechos".

Pese a que la CPR no cuenta con disposiciones expresas de reconocimiento de derechos culturales en general, ni de derechos para los pueblos indígenas $\mathrm{u}$ otros grupos, en particular, en perspectiva hermenéutica, la justificación del derecho fundamental a la identidad cultural se articula desde el artículo 5 inc. $2^{\circ}$ de la CPR que reenvía a los tratados internacionales en materia de derechos humanos ratificados y vigentes en Chile $^{93}$.

\footnotetext{
92. Sobre la idea de "grupo minoritario" v. Nota 4. En Chile, por ejemplo, existen grupos afrodescendientes con presencia relevante en la Región de Arica y Parinacota. Recién en abril de 2019 fueron reconocidos por la ley 21.151 que "Otorga reconocimiento legal al pueblo tribal afrodescendiente chileno" ("a su identidad cultural, idioma, tradición histórica, cultura, instituciones y cosmovisión" art. 1), aunque a la fecha no han sido objeto de reconocimiento constitucional (DUCONGE y MENARA, 2014; GREEN, 2015; INE, 2014).
}

93. Se describe en el Capítulo 3. de este trabajo. V. FAUNDES (2020a) p. 80. 


\subsection{Interpretación de la CPR y precedentes destacados en relación al derecho a la identidad cultural}

La jurisprudencia chilena de los tribunales superiores chilenos, en un amplio espectro de precedentes (2009-2019) ${ }^{94}$, ha reconocido los derechos de los pueblos indígenas como parte del bloque de constitucionalidad ${ }^{95}$, la cual, a su vez, ha sido objeto de muy diversa bibliografía ${ }^{96}$. Para los efectos de este trabajo centrado en la cultura jurídica, una de cuyas dimensiones se expresa mediante la jurisprudencia, solo reseñaremos algunas decisiones paradigmáticas, centrados en la interpretación de alcance constitucional. La primera selección que se presenta es genérica, para mostrar la mirada de las cortes en relación al derecho a la identidad cultural ${ }^{97}$. En un segundo grupo, destacamos algunas sentencias en materia penal, para confluir con el específico del estudio socio-etnográfico, delimitado a los tribunales con dicha competencia.

94. Se han pesquisado, entre 2009 y 2019, 47 causas de la Corte Suprema y 267 de cortes de apelaciones (sin contar el Tribunal Constitucional, ni los tribunales ambientales) que refieren a derechos indígenas y en alguna medida al derecho a la identidad cultural. Los casos son temáticamente dispersos y muchas veces hay decisiones contradictorias respecto de supuestos similares -lo que examinamos brevemente en este apartado-. Muchos casos son sobre consulta indígena y temas de tierras, mientras ha sido más escaza la jurisprudencia en materia penal (20 casos de Cortes de Apelaciones y 5 de la Corte Suprema, en su mayoría referidos a violencia intrafamiliar y acuerdos reparatorios). Datos de producción propia v. Informe final Proyecto FONDECYT Iniciación N ${ }^{\circ} 11161079$ ).

95. FAUNDES (2015); AYLWIN et al. (2013).

96. En términos bibliográficos, entre muchos otros, v. AYLWIN et al. (2013); CARMONA (2013); CASTRO Y VERGARA (2009); DPP (2017); LÓPEZ y MOHR (2014); ROJAS (2014).

97. El Tribunal Constitucional chileno, más los que denominamos "tribunales superiores de justicia" (cortes de apelaciones y Corte Suprema) hacen control concentrado o difuso o de la Constitución, según el caso, y su competencia material es general (civil, penal, ambiental, laboral, familia, etc.). Por ello, la primera selección de casos que presentamos comprende sentencias de diversas materias en que el núcleo normativo constitucional de base, como fundamento preponderante, es el principio de igualdad y no discriminación en relación al derecho a la identidad cultural. 


\section{Precedentes de cortes con alcance constitucional en Chile:}

\section{"Francisca Linconao con Forestal Palermo":}

El primer fallo en Chile en que se aplicó el Convenio $\mathrm{N}^{\circ} 169$ de la OIT fue "Francisca Linconao con Forestal Palemo (2009) ${ }^{98}$. En este caso, una machi ${ }^{99}$ denunció el daño ambiental contra manantiales (menoko) sagrados, bosque nativo y de hierbas medicinales (lawen) en esos espacios, fundamentales para el desarrollo de su actividad tradicional de salud, que afectaban su espiritualidad y la de la comunidad. Dijeron los jueces en este caso:

“... el artículo 5 inciso segundo del Código Político señala que el ejercicio de la soberanía tiene como límite el respeto a los derechos esenciales que emanan de la naturaleza humana y... es deber de los órganos del Estado respetar y promover tales derechos [...] especial atención deben tener los Estados en la protección y preservación de las tierras y culturas indígenas en todas sus manifestaciones..."

“... el Derecho a Vivir en un medio libre de contaminación para la actora se ha visto afectado, puesto que se vulnera la integridad física y psíquica de esa etnia, se agravia en su naturaleza humana y la calidad de vida y en la protección de sus sistemas de salud, puesto que el Menoko es un lugar, espacio cultural, que no debe ser molestado, sino que siempre protegido" ${ }^{100}$.

\section{Tribunal Constitucional, TC $2552-2013^{101}$ :}

En el marco de un juicio relativo a tierras indígenas desarrollado conforme el procedimiento especial de la Ley Indígena 19.253, una de las partes no indígena alegó la inconstitucionalidad de este procedimiento. Dijo el Tribunal Constitucional:

“... el Tribunal ha validado los mecanismos de afirmación positiva que establece el legislador. Estos son sistemas destinados a proteger a determinados grupos o sectores de personas que han sido históricamente minusvalorados. Son mecanismos cuyo propósito es asegurar la efectiva igualdad ante la ley... Estas medidas buscan que las personas tengan las mismas oportunidades en el punto de partida (artículo $1^{\circ}$ inciso final, de la Constitución)...

98. Linconao Francisca con Forestal Palermo (2009). Confirmada, Corte Suprema (30.11.2009).

99. Autoridad tradicional del Pueblo Mapuche en el ámbito de la salud.

100. Linconao Francisca con Forestal Palermo (2009), cons. $3^{\circ}, 4^{\circ}, 13^{\circ}$.

101. Tribunal Constitucional (24.12.2015). 
Este Tribunal [considera] que los indígenas [son] un grupo "socio-económicamente vulnerable, con la especificidad histórica cultural que le es propia”;

“... la Constitución no establece un tipo de propiedad determinada. Reconoce la propiedad 'en sus diversas especies'. No hay una sola propiedad, sino tantas propiedades como el legislador configure. No existe una propiedad general y propiedades especiales; existen sólo propiedades distintas, con estatutos propios. No hay en la Constitución un modelo a partir del cual se construyan las distintas propiedades".

“... no solamente hay normas nacionales que el Estado de Chile debe respetar, sino tratados internacionales. Uno de ellos es el Convenio $\mathrm{N}^{\circ} 169 \ldots$ En este sentido, el Convenio establece que 'deberán adoptarse las medidas especiales que se precisen para salvaguardar las personas, las instituciones, los bienes, el trabajo, las culturas y el medio ambiente de los pueblos interesados"'102.

\section{Caso del Cerro Ceremonial Topater: "Herminia Toroco Herrera y Amelia Mama- ni Charcas con Sociedad Inversiones e Inmobiliaria Villa Nueva S.A.”103}

En el caso conocido como del Cerro ceremonial Topáter de Calama, se intentó realizar un proyecto inmobiliario que afectaría el Cementerio Topater y el Cerro Fundición que componen un complejo ceremonial donde comunidades indígenas likan antai, quechua y aymara rinden culto a sus antepasados. La sentencia de la Corte Suprema ordenó la paralización de las obras considerando que:

“... la [recurrida] no ha procedido con sujeción estricta... a los preceptos del mentado Convenio 169 de la OIT [...] tratándose de un cementerio que cobija, al modo silencioso como lo hacen las reminiscencias históricas, innúmeras evidencias no solamente de existencia de vida de personas que habitaron la región en época pre incásica más o menos remota; no solo eso, sino objetos múltiples que dan cuenta de prácticas, usanzas y/o costumbres propias de un apogeo cultural de etnias cuyos actuales representantes consideran, como parece natural a la especie humana, de un valor superior e incluso sagrado, con ribetes de religiosidad precolombina.

102. En los párrafos siguientes la sentencia transcribe íntegramente los artículos 14 y 15 del convenio en relación con las tierras de uso tradicional de los pueblos indígenas y el derecho a los recursos naturales que existen en sus territorios."

103. Herminia Toroco Herrera y Amelia Mamani Charcas con Sociedad Inversiones e Inmobiliaria Villa Nueva S.A. (2013). 
... la intromisión desordenada, desautorizada e inconsulta de inversionistas que pretenden ejecutar un proyecto inmobiliario que, en lo físico, se ubicaría a no más de 35 metros de distancia del punto crítico donde se resguarda tal patrimonio, sumado al tráfago propio del hábitat en el que se desenvolvería la población que allí resida, perturba el derecho legítimo que tienen las recurrentes, tanto al libre ejercicio y desarrollo de sus creencias religiosas y ritos sagrados, garantido para ellas y sus congéneres [por el art. $19 \mathrm{~N}^{\circ}$ 6 de la Constitución] de modo que, de tolerar que se los pase a llevar, se los diferenciaría, arbitrariamente". Y... que los actos recurridos contrarían "la garantía de igualdad y no discriminación que sienta el numeral $2^{\circ}$ del propio artículo 19".

\section{“Comunidad indígena Entuco contra Municipalidad de Padre las Casas"104}

La Comunidad Entuco del Pueblo Mapuche reclamó la falta de consulta y buscaba evitar la construcción de una media luna de rodeo en un terreno colindante a las tierras de la comunidad. Señaló la Corte Suprema:

“... Que el emplazamiento de la media luna tiene por objeto la difusión de costumbres y la realización de un rodeo anual. Éstas no son costumbres indígenas. Esto no significa que ellas no puedan manifestarse, pero una finalidad del Convenio No. 169... es precisamente dar lugar a un proceso de consulta con la finalidad de alcanzar un acuerdo con las comunidades afectadas... Este acuerdo... tiene por objeto facilitar la integración pacífica de tradiciones culturales diversas. Así se evita que la cultura dominante se imponga sin siquiera considerar los intereses culturales afectados".

“... la medida puede tener un impacto significativo sobre sus tradiciones y costumbres ancestrales, sobre todo si se trata de canalizar una actividad deportiva de la herencia cultural antagónica a la mapuche".

\section{"Remingual Lemui Cristobal con Ilustre Municipalidad de Osorno":}

En este caso, un machi denunció su afectación como consecuencia del uso no autorizado de su fotografía en un calendario municipal. La Corte Suprema acogió la demanda basada en:

104. Comunidad indigena Entuco contra Municipalidad de Padre las Casas (2016). 
“... el menoscabo a su credibilidad como autoridad del pueblo originario al que pertenece, teniendo en consideración además, que su imagen es publicada en un contexto de tradiciones chilenas, no obstante que su condición de machi se contextualiza dentro de la cultura y creencias del pueblo mapuche"105.

\section{"Juan Segundo Pichún contra Sebastián Pinera Echeñique"}

El Lonk ${ }^{107}$ Juan Pichún recurrió contra el entonces candidato a presidente de Chile Sebastián Piñera porque utilizó su imagen como Lonko, de la comunidad mapuche Temulemu de Traiguén, en la propaganda de la franja política electoral televisiva, sin autorización previa. Se trataba del video de un diálogo sostenido por ambos en el marco de un programa de televisión difundido ampliamente.

La sentencia -confirmada por la Corte Suprema- desestimó el recurso en base al contexto público de las imágenes y porque el Sr. Piñera no habría usado la calidad de autoridad tradicional del recurrente. Dijo la Corte de Apelaciones de Temuco:

“... se trata de grabaciones que siempre estuvieron destinadas a su difusión pública, en el contexto se una serie de programas emitidos por diversos canales de televisión, en forma previa a las elecciones primarias presidenciales, y con el objeto de dar a conocer a la ciudadanía las propuestas y programas de gobierno de los distintos candidatos.

En efecto, el diálogo que se produjo... en sus calidades de candidato presidencial y autoridad ancestral mapuche respectivamente, y tratándose por ende de personajes de connotación pública, fue ampliamente difundido por diversos medios de comunicación digitales".

\section{“Curin Tromo Celmira con Bosques Arauco S.A." 108}

Una mujer mapuche demandó a una empresa forestal reivindicando el predio que poseía materialmente de forma histórica, porque la empresa demandada lo tenía formalmente inscrito a nombre disputando el dominio. Dijo la Corte de Apelaciones de Temuco:

105. Remingual Lemui Cristobal con Ilustre Municipalidad de Osorno (2013).

106. Juan Segundo Pichún contra Sebastián Pinera Echeñique (2017).

107. Máxima autoridad política tradicional de la Comunidad Mapuche y en términos tradicionales quien tiene a su cargo la justicia de la comunidad conforme el derecho propio mapuche.

108. Curin Tromo Celmira con Bosques Arauco S.A. (2009). 
"Que tratándose la cosa reivindicada de tierra indígena, no corresponde aplicar de manera estricta la teoría de la posesión inscrita consagrada en el Código Civil... En el caso en estudio... debemos tener presente los principios recogidos en el artículo 1 de la Ley 19.253 y en el Convenio $\mathrm{N}^{\circ} 169$ de la O. I. T. sobre Pueblos Indígenas y Tribales, publicado en al Diario oficial el 14 de octubre de 2008, que establece que al aplicar las disposiciones del convenio deberán reconocerse y protegerse los valores y prácticas sociales, culturales, religiosos y espirituales propios de dichos pueblos... deberán tomarse debidamente en consideración sus costumbres o su derecho consuetudinario (artículo $8 \mathrm{~N}^{\circ}$ 1); las autoridades y los tribunales llamados a pronunciarse sobre cuestiones penales deberán tener en cuenta las costumbres de dichos pueblos en la materia (artículo $9 \mathrm{~N}^{\circ} 2$ ). Deberán respetarse las modalidades de transmisión de los derechos sobre la tierra entre los miembros de los pueblos interesados establecidos por dichos pueblos (artículo $\left.17 \mathrm{~N}^{\circ} 1\right)^{109}$.

\section{Precedentes de tribunales superiores en materia penal:}

\section{"Maria Isabel Jamerne Jamerne Contra Marta Angelina Coliñanco Huechulef”"10.}

El caso corresponde a una querella por usurpación presentada por una persona no indígena contra una mujer mapuche que poseía materialmente la propiedad hace más de 30 años y, previamente, fueron poseídas por personas mapuche ya fallecidas, de forma continua desde que se otorgó el Título de Merced sobre esas tierras en $1912^{111}$. Asimismo, en defensa de la querellada se argumentó que no era un caso penal ("atipicidad"), de usurpación porque se discutía una cuestión "civil" previa sobre la propiedad conforme la costumbre mapuche y el reconocimiento del uso tradicional de la tierra que contempla el Convenio 169 de la OIT (arts. 13 y 14). La Corte de Apelaciones de Temuco confirmó la sentencia penal que condenó por usurpación no violenta a la mujer mapuche, considerando que no se trataba de tierra indígena. En sus fundamentos señaló la Corte:

109. Curin Tromo Celmira con Bosques Arauco S.A. (2009). En el mismo sentido: Ingeborg Rendel Augant con Comunidad Indígena José Gineo Nanco (2010).

110. Maria Isabel Jamerne Jamerne Contra Marta Angelina Coliñanco Huechulef (2013).

111. Título de Merced № 2.387 de 30 de diciembre de 1912. 
"De la normativa y de los hechos expuestos, se concluye con absoluta claridad, que la ocupación de tierras indígenas, por parte de personas o comunidades indígenas, a pesar de carecer de título, en los términos de la legislación civil, es un accionar lícito, tolerado y reconocido por el legislador, estando obligado el Estado a reconocer el derecho de propiedad y posesión de las tierras indígenas que tradicionalmente ocupan los pueblos indígenas, conforme al Convenio 169 de la OIT."

“... el juez de primer grado... luego de un análisis detallado especialmente en cuanto a ser o no tierra indígena, concluy[ó] que no lo es porque al producirse la división de la Comunidad Indígena Antonio Punulef, el 5 de Octubre de 1993, se adjudicó a Rosa Coliñanco Llancafilo la mencionada Hijuela $\mathrm{N}^{\circ} 110$ y la compraventa que ella hizo a los querellantes lo fue por Escritura Pública de 04 de Octubre de 1993, con anterioridad a la vigencia de la ley 19.253, sujetándose en cuanto a los trámites y formalidades a la ley vigente, esto es, el Decreto Ley $\mathrm{N}^{\circ} 2.568$, de manera que no habría infracción a la ley indígena $\mathrm{N}^{\circ} 19.256$ y del Convenio $\mathrm{N}^{\circ} 169^{\prime 112}$.

\section{“Contra/ José Patricio Maripil Porteño y otros" ("Malón de Caiñicu”)"113}

Corresponde a un caso de delito de homicidio en que se aplicó una atenuante de responsabilidad penal basada en razones socioculturales. Dijo la Corte:

“... que la Comunidad de Cauñicú literalmente defendió su territorio sobre la base de un sentido de identidad cultural... el acuerdo de desalojo convenido entre los miembros de la entidad cultural, debe interpretarse en el contexto de la aplicación de un mecanismo propio del "Ad Mapu", así como el ejercicio del derecho consuetudinario mapuche...."

“... Que este amparo de la tierra y de su identidad cultural, revela que para este pueblo indígena las infracciones que vulneran la propiedad son de una gravedad relevante, no tanto por el detrimento patrimonial de la víctima, sino casi exclusivamente por atentar contra un orden colectivo y el mentado equilibrio del cosmos".

112. Maria Isabel Jamerne Jamerne Contra Marta Angelina Coliñanco Huechulef (2013). La Corte Suprema declaró inadmisible el recurso de queja por consideraciones de forma, sin entrar al fondo (por 3 votos a 2). Corte Suprema (16.05.2013).

113. Contra/ José Patricio Maripil Porteño y otros (2012). 
“...[el] informe antropológico... corresponde a una experticia confeccionada en virtud del mandato estatuido en el artículo 54 de la Ley $\mathrm{N}^{\circ} 19.253 \ldots$ en armonía con lo preceptuado en los artículos 5, 6, 8, 9 y 10 del Convenio $\mathrm{N}^{\circ}$ 169, de la O.I.T..., normativas acordes, además, con lo preceptuado en los artículos $5^{\circ}$ de la Constitución Política de la República, 26 y 27 del [PIDCP]..” “... existen antecedentes suficientes y coherentes para considerarla como "aminorante" de la conducta demostrada por los enjuiciados, recepcionando así el derecho consuetudinario y hábitos del pueblo pehuenche como fuente de derecho, de modo de hacer compatible la sanción penal prevista en nuestra legislación general con las características económicas, sociales y culturales de esa etnia" ${ }^{114}$.

\section{Análisis de los precedentes revisados ${ }^{15}$ :}

Como se constató, la CPR no contempla en su texto derechos culturales, ni en general, ni para pueblos indígenas u otros grupos. De esta forma, el reconocimiento y protección constitucional del derecho fundamental a la identidad cultural supone un ejercicio de interpretación, en relación con los instrumentos internacionales en materia de derechos humanos que contemplan el derecho común a participar en la vida cultural y los derechos de los pueblos indígenas y otros grupos, específicamente. Todo ello, en relación con otros derechos fundamentales contemplados en la Carta Fundamental. Entonces, la jurisprudencia fundó el derecho a la identidad cultural en una visión amplia del principio de igualdad y del respeto de la dignidad humana ${ }^{116}$, de conformidad con el artículo $1^{\circ}$ de la CPR que establece que es deber del Estado

\footnotetext{
114. Contra/ José Patricio Maripil Porteño y otros (2012).
}

115. Por una extensión no desarrollaremos otros tres ámbitos relevantes de la jurisprudencia penal: i) casos referidos al porte, comercialización y uso de hoja de coca, cuya licitud se sostiene en el derecho a la identidad cultural, v. BARRIENTOS (2008); DPP (2013); ii) casos de acuerdos reparatorios en causas de violencia intrafamiliar suscitadas entre indígenas, conforme la aplicación de los artículos 9 y 10 del Convenio 169, muy debatidos en relación a la protección de la mujer frente a la violencia. Entre otros v. CARMONA (2015); FAUNDES (2019a); FERNÁNDEZ (2018); FERNÁNDEZ y FAUNDES (2019); PALMA y SANDRINI (2014); NASH et al. (2013); VILLEGAS y MELLA (2017) pp. 151-163; iii) casos referidos al tratamiento diferenciado en el cumplimiento de las penas (artículo 10 del Convenio N¹69), v. UC Temuco y DPP (2017).

116. Linconao Francisca con Forestal Palermo (2009); Alejandro Papic Domínguez con Comunidad Indigena Aymara Chusmiza y Usmagama (2009) cons. $4^{\circ}$ y $13^{\circ}$. 
"asegurar el derecho de las personas a participar con igualdad de oportunidades en la vida nacional" y el derecho a "intervenir con igualdad de condiciones a su mayor realización espiritual y material posible”. Todo, en relación al artículo 19 que asegura a todas las personas: $\left(\mathrm{N}^{\circ}{ }_{2}\right)$ "La igualdad ante la ley", $\left(\mathrm{N}^{\circ} 4\right)$ el derecho a la vida privada y la honra de la persona y la familia, $\left(\mathrm{N}^{\circ} 6\right)$ la libertad de creencias y de religión, $\left(\mathrm{N}^{\circ} 8\right)$ el derecho a vivir en un medio ambiente libre de contaminación y $\left(\mathrm{N}^{\circ} 24\right)$ el derecho de propiedad, entre otros ${ }^{117}$. Conforme con ello, la protección del derecho a la identidad cultural de los pueblos indígenas, sus comunidades y de otros grupos y sus respectivos miembros, suponen un ejercicio hermenéutico de cortes con competencia constitucional que articulan estos derechos fundamentales con los derechos culturales en una perspectiva "pro persona" ampliando el alcance de los derechos positivamente estatuidos ${ }^{118}$.

Conjuntamente, a la luz del artículo 5 inciso $2^{\circ}$ de la CPR, la jurisprudencia chilena ha reconocido en sus fallos el derecho a la identidad cultural de los pueblos indígenas o, a lo menos, la obligación del estado de dar protección a las expresiones culturales (que desde nuestro enfoque son constitutivas del derecho a la identidad cultural), con diversos alcances, invocando el Convenio 169 de la OIT, como tratado internacional de derechos humanos vigente en el país, entre otros instrumentos ${ }^{119}$.

Bajo la línea de precedentes descritos se observa una interpretación extensiva y cautelar, en que los sentenciados hacen dialogar las fuentes normativas internas con las fuentes de Derecho Internacional, a partir del propio texto constitucional. Se observa un ejercicio hermenéutico que articula las fuentes y evita así las resistencias de una aplicación "frontal" del Control de Convencionalidad"120. Así se observa en los casos de la Machi Francisca Linconao, del Cementerio Topater o de la Comunidad Entuco (entre muchos otros).

En los casos relativos al derecho a la protección de la propia imagen de autoridades tradicionales indígenas, si bien las resoluciones revisadas aparecen como contradictorias en sus decisiones finales, es interesante un análisis en profundidad de su ratio decidendi. En un caso se protegió la propia imagen de una autoridad ancestral mapuche (machi) y en el otro no (lonko). Sin embargo, en ambos: (i) se reconoce a los recurrentes la calidad, en sí, de autoridad tradicional del Pueblo Mapuche y en ese

117. v. FAUNDES (2020a).

118. v. AGUILAR y NOGUEIRA (2016).

119. CS Rol 7287-2009, 30 nov. 2009; Alejandro Papic Domínguez con Comunidad Indígena Aymara Chusmiza y Usmagama (2009); Comunidad indigena antu lafquen de huentetique contra Comision Regional del Medio Ambiente Región de los Lagos (2012). En la misma línea los fallos del Tribunal Constitucional chileno: TC 2387-2012 (23.01.2013); TC 2552-2013 (24.12.2015).

120. HENRIQUEZ y MORALES (2017); NOGUEIRA y AGUILAR (2017). 
sentido, se la estima bajo una esfera especial de resguardo, constituida por el rol de autoridad tradicional, en el marco de la cosmovisión indígena mapuche que el Estado ampara; ii) en el primer caso se reconoce expresamente el derecho a la imagen como una dimensión de la identidad cultural y derecho fundamental que requiere tutela constitucional; iii) en el segundo, en abstracto, la Corte asume que la identidad cultural es objeto tutela constitucional, pero sostiene una hipótesis de facto (discutible o no) que la lleva a descartar la protección en el caso en concreto ${ }^{121}$.

En estas sentencias relativas al derecho a la propia imagen y el derecho a la identidad cultural, se aprecia el "doble flujo" -antes referido-, en orden a que, frente a situaciones de base de la misma naturaleza, en un caso la hermenéutica judicial buscó la protección de la identidad cultural, mientras en el segundo,-descartando la tutela reclamada en concreto- decidió utilizando una argumentación mucho más positivista que no priorizó, como finalidad, la protección del derecho fundamental de la persona a su identidad cultural.

Por su parte, en armonía con el criterio hermenéutico de base que se abre al reconocimiento del derecho a la identidad cultural, el Tribunal Constitucional admite la existencia de estatutos o normativas especiales, en perspectiva afirmativa para la protección de grupos vulnerables, en el que incluye a los pueblos indígenas y la protección de su cultura. En particular, para esta corte constitucional, el derecho a la identidad cultural se vincula hermenéuticamente con otros derechos fundamentales, tales como la protección del medio ambiente, su hábitat y el derecho de propiedad en relación a sus tierras, territorios y recursos naturales.

Sobre las sentencias revisadas en materia penal, podemos ver cómo en el caso contra Marta Angelina Coliñanco, el juez penal y la corte revisora (en recurso de nulidad), por una parte, coinciden en la doctrina civil que ampara la posesión material histórica, de forma preferente a la posesión inscrita "de papel", en particular en favor de personas y tierras indígenas conforme el Convenio $\mathrm{N}^{\circ} 169$ de la OIT (en relación a la Ley 19.253 que establece la protección de las tierras indígenas en el ámbito interno $)^{122}$. Sin embargo, por otro, en su interpretación formal y muy discutible de la

121. En esta línea, en la sentencia de la Corte suprema de este caso, el Ministro Muñoz manifestó un voto disidente en que, más allá de la exposición comunicacional voluntaria del Lonko Pichún en el programa televisivo -que argumentó la mayoría-, estima, que debió consentir expresamente para efectos del uso político de su imagen. Juan Segundo Pichún contra Sebastián Pinera Echeñique (2017).

122. El art. 12 inc. $1^{\circ}$ de la Ley 19.253, señala que son tierras indígenas todas las actualmente ocupadas por personas y comunidades indígenas, provenientes de títulos de los títulos que dicha disposición enumera, entre ellos, los Títulos de Merced. 
aplicación de la Ley Indígena en el tiempo, desestimaron la defensa, sosteniendo que no se trataba de "tierra indígena" ${ }^{123}$. Como podemos observar, la conducta sancionada como ilícita penalmente - "usurpación", debió haber sido considerada lícita conforme el elemento civil del tipo penal, porque no existía "cosa ajena", sino una disputa por la propiedad ${ }^{124}$. Es más, se trata de posesión legítima de las tierras considerando la posesión histórica tradicional como expresión de su derecho a la identidad cultural mapuche.

Precisamente, en otros casos (aunque en materia civil) como "Curin Tromo Celmira con Bosques Arauco S.A." ${ }^{25}$ e "Ingeborg Rendel Augant con Comunidad Indígena José Gineo Nanco" ${ }^{126}$, la decisión judicial, precisamente, consideró de manera preferente el uso histórico ancestral de la tierra, por sobre la inscripción formal de la propiedad por parte de privados no indígenas ${ }^{127}$. Así, bajo la línea argumental que venimos desarrollando, la tipicidad de los delitos imputados o su antijuricidad (según sea el enfoque dogmático penal que se plantee) ${ }^{128}$, ocurre cuando la decisión del juez o la Corte se descontextualiza de la realidad histórico cultural de los hechos. Entonces, existiendo en ambos casos un mismo bien en disputa (la propiedad sobre tierras indígenas de uso tradicional), ergo, mismas razones de justicia material, es evidente que en el segundo caso hay una hermenéutica penal que ignoró los alcances del derecho fundamental a la identidad cultural y sus efectos en la decisión penal del caso.

En el sentido anterior, en términos penales, debió estimarse que se trató del "ejercicio legítimo de un derecho" (derecho, autoridad, oficio o cargo ${ }^{129}$ ) lo que determinaba la "antijuricidad" o derechamente "atipicidad" en el caso. Se trata del ejercicio del derecho de que gozan los pueblos indígenas a las tierras que ocupan o poseen "de una u otra manera", así como a los recursos naturales existentes en estas tierras y territorios. El Convenio 169 de la OIT (art. 9), como instrumento vinculante para el Estado de Chile, obligaba en el caso a ponderar las condiciones sociales y culturales

123. La Corte Suprema finalmente desechó el caso, en voto dividido (tres a dos). Corte Suprema (16.05.2013).

124. BINDER (2004) pp. 272-274; KOSVSKY (2014); HUALPA (2014) pp. 239-293.

125. Curin Tromo Celmira con Bosques Arauco S.A. (2009).

126. Solo anotado previamente como referencia a: Ingeborg Rendel Augant con Comunidad Indígena José Gineo Nanco (2010).

127. Sobre la materia v. FAUNDES (2015); ROJAS (2014).

128. FAUNDES (2019a).

129. Actúa justificado quien ejercita un derecho que le ha sido conferido por el ordenamiento jurídico (art. $10 \mathrm{~N}^{\circ} 10$ del Código Penal). Puede tratarse de una facultad expresamente contemplada en la ley, o bien, puede desprenderse de normas consuetudinarias. CURY (2005) pp. 381-382. 
de los miembros de los pueblos indígenas cuando son objeto de persecución penal y, además, a ponderar los antecedentes armónicamente con los artículos 13 y 14 del mismo tratado de derechos humanos que protege las tierras y territorios indígenas.

En el caso del "Malón de Caiñicú”, visualizamos que es el propio juez penal (y o las cortes revisoras) quien introduce en su ponderación los factores culturales de contexto (acreditados mediante peritaje antropológico) asociados al derecho a la identidad cultural y de esa forma reduce la sanción.

Los casos vistos muestran que no existe armonía en la comprensión judicial de la identidad cultural en materia penal, por ello cuando los jueces han incluido elementos culturales, evidencian, tan solo, un cambio recién emergente ante la comprensión hegemónica en materia penal ${ }^{130}$. En este sentido, es emblemático el caso de Gabriela Blas ("caso de la Pastora Aymara") quien fue condenada criminalmente por la muerte negligente de su hijo de dos años, bajo un amplio marco de preconcepciones, prejuicios y prácticas judiciales discriminatorias, tanto en perspectiva de género como identitaria culturales. Estos hechos finalmente fueron admitidos por el Estado de Chile que llegó a una solución amistosa del caso ante la Comisión Interamericana de Derechos Humanos ${ }^{131}$.

\subsection{Estudio de la cultura jurídica chilena y el derecho a la identidad cultural des- de la percepción los actores jurídicos ${ }^{132}$}

En este apartado presentamos una síntesis de las entrevistas a actores jurídicos chilenos, sintetizando una aproximación a sus concepciones de la cultura jurídica y la relación de ella con el derecho a la identidad cultural. Así, en esta parte, la propuesta metodológica busca: (i) una descripción de la cultura jurídica desde la comprensión de los operadores del campo jurídico; (ii) una descripción de los actores del campo jurídico de cómo esa cultura jurídica ha podido recepcionar el derecho a la identidad cultural.

130. FAUNDES (2019a).

131. Gabriela Blas Blas y su hija C.B.B., Chile (2018), CIDH, Informe $\mathrm{N}^{\circ} 138 / 18$.

132. Gran parte de las entrevistas citadas en este apartado fueron realizadas por el tesista en ciencias jurídicas asociado al proyecto Fondecyt 1170505, Darwin Paillacura. 


\section{Entrevistas a los actores jurídicos}

\section{¿Qué entiende por cultura jurídica?}

Señala un abogado defensor de indígenas:

"La cultura jurídica es como nos regimos, partiendo del hecho de que hay tres poderes del Estado; Poder ejecutivo, Legislativo, y Judicial, y la Carta Magna que es la Constitución yo creo que todos en cierto modo tenemos un poquito de cultura jurídica. Después uno ya empieza a tener un concepto más técnico de cultura cuando entra a la universidad, a saber, la terminología jurídica, a usar correctamente el vocabulario jurídico también a la hora de enfrentarse a un proceso oral o a un proceso escrito, utilizar correctamente los tecnicismos o las palabras que uno pudiese emplear" ${ }^{133}$.

Un juez señala que la cultura jurídica supone un aprendizaje formal e informal de diversas valores, principios y actitudes por adoptar en el actuar profesional, en este sentido que "en general la cultura jurídica son los principios que abordan el derecho, la buena fe, el principio de la libertad contractual en el derecho civil, el principio de indubio pro reo, también el principio de igualdad ante ley, el debido proceso" ${ }^{134}$.

Mientras otro defensor enfatiza sobre los aspectos prácticos, como los "conocimientos propios que se ven el ámbito jurídico y que involucran a todas las partes y que van creando una cultura" y son el quehacer cotidiano de todos los operadores del sistema $^{135}$. Asimismo, otro de los magistrados advierte que la cultura jurídica en Chile sigue muy anclada en el formalismo:

“... hay una cultura jurídica en Chile dada en parte por la estructura judicial que tenemos de una suerte como de respeto cuasi religioso a ciertas maneras de hacerse las cosas a veces la falta de cuestionamiento ante ciertas decisiones solo porque se apartan de lo que algún superior a dicho en sentido diverso. (...) [Existe un] gran culto al formalismo, sin duda, un gran culto al statu quo, a lo que se encuentra supuestamente asentado y un cierto temor al cambio de enfoque que puede aplicar un cambio de razonamiento jurisprudencial"136.

\section{Entrevistado E1.}

134. Entrevistado E2.

135. Entrevistado E3.

136. Entrevistado E4. 
También observa la permanencia de rasgos de este formalismo en la actualidad y a pesar de los cambios producidos tanto en el derecho chileno como en la sociedad chilena. Afirma que el trato dado a los jueces tiene resabios incluso monárquicos internalizados en la forma de funcionar de los tribunales como una "cultura de pensamiento cuasi religioso o cuasi mágico de la posición de esta figura dentro del aparato judicial... siempre tan absurdo, porque vivimos en una república democrática" ${ }^{137}$.

\section{¿Identifica el derecho a la identidad cultural en la cultura jurídica chilena?:}

Para un abogado que se desempeña como defensor penal privado, la cultura jurídica chilena contiene un "excesivo o fuerte legalismo" focalizada en el juez como "tercero imparcial que está proporcionado por la institucionalidad del Estado" ${ }^{138}$.

Un defensor penal público estima que los actores jurídicos, como jueces, fiscales, defensores y los abogados, en general, responden a una misma formación universitaria que han estudiado todos lo mismo, bajo "una misma línea de pensamiento" que determina un discurso donde "todos somos iguales, todos somos chilenos, a todos se les aplica la misma ley; las leyes son las que dicta nuestro parlamento". Continúa diciendo que con el pasar del tiempo los abogados ejercen diversas funciones (jueces, fiscales, defensores) "pero en su origen estudiamos lo mismo", pero en ese contenido común "no estudiamos la identidad cultural del Pueblo Mapuche"139.

Consultado sobre el derecho fundamental a la identidad cultural, el ministro de la Corte Suprema entrevistado señala que:

"La diversidad existe de todas formas y en los últimos años se ha puesto más de manifiesto con la evolución misma de la sociedad y yo pienso que es un gran desafío para las generaciones particularmente las un poco más mayores porque la gente joven, los estudiantes de colegios, ya lo ve en el colegio, lo viven y lo tienen incorporados a su manera de ser, es a los más mayores a los que nos cuesta más.

Es un gran aporte para la cultura en general, no es una sola línea, sino que son varias líneas que se incorporan, se entrecruzan y permiten ampliar la visión, por ejemplo, con lo que piensa la persona indígena, lo que piensa la persona migrante, lo que piensa la persona homosexual que se yo, hay toda una cantidad de variantes que uno incorpora y al incorporarlas nace un sentido más respetuoso y un sentido más democrático".

\section{Entrevistado E4.}

138. Entrevistado E5.

139. Entrevistado E6. 
Sobre el ejercicio del derecho a la identidad cultural por parte de personas indígenas en los procesos judiciales, el mismo magistrado del máximo Tribunal indica:

“... todas las personas en situación de vulnerabilidad tendrían que [tener] un trato especial sin producir un desequilibrio, la idea siempre es que las partes en los conflictos estén en equilibrio, suponemos que las personas en situación de vulnerabilidad está en desequilibrio, entonces todo lo que nosotros hagamos desde una ley hasta una buena práctica, es para que estén en equilibrio y ahí entonces poder administrar justicia. Entonces si al migrante nosotros le ponemos un traductor lo hemos colocado en situación de equilibrio y le hemos permitido al juez además entender, ese es el aporte de todas estas medidas que apoyen y lo propio con la persona indígena porque puede haber alguien que le explique al juez cuáles son los pensamientos, las costumbres, las tradiciones religiosas, etc. y de esa manera se produce el equilibrio".

\section{¿Qué interacciones visualiza entre la cultura jurídica y el derecho a la identidad cultural?}

Expresa uno de los jueces penales que "en todo caso, con la interrelación que hay, todas las personas conocen los tipos penales, entonces no hay mayor diferenciación entre personas de la etnia mapuche y personas chilenas"140. Pero, en sentido opuesto, un defensor penal afirma que en la actualidad debe operar la "aplicación del Convenio 169", aunque considera que su aplicación no ha llegado a alcanzar un cambio en el Derecho. Destaca como hito, que marca un cambio en el reconocimiento de derechos indígenas, el caso de la machi Francisca Linconao porque en ese tiempo (2009) "aún no se había implementado el Convenio 169 en Chile, pero se entendió en esa resolución que se debía aplicar los derechos de los pueblos indígenas"141.

El Ministro de la Corte Suprema, sobre la recepción de la identidad cultural en los tribunales, señala:

"Yo pienso que... los esfuerzos se han desplegado en algunos casos por algunos magistrados pero no es todavía suficiente porque esto es un proceso que está en marcha, entonces el acceso a la justicia de las personas en situación de vulnerabilidad es algo que de a poco se ha ido incorporando a la cultura de los magistrados y del personal de los tribunales y este tema de la diversidad cultural también. Entonces paulatinamente tendremos que ir avanzando en eso".

140. Entrevistado E7.

141. Entrevistado E8. 
Indica que esos avances se pueden constatar, por ejemplo, en la forma cómo se trata hoy a un migrante que llega a un tribunal, se mira con un enfoque diferente:

“... ya no es Pedro contra Juan, sino que es Pedro contra Juan migrante, Pedro contra Juan indígena, Pedro contra Juana mujer migrante e indígena, por decir".

Explica así que hoy existe una visión diferente porque se ha hecho un esfuerzo, "hay múltiples actividades en los tribunales" y considera que el reconocimiento de las diferencias culturales debe llegar a ser general, porque hasta ahora solo ha ocurrido en algunos casos emblemáticos, pero que falta su internalización por los jueces.

En particular, sobre cómo el sistema de justicia chileno enfrenta las demandas por derechos del Pueblo Mapuche, indica el ministro de la Corte Suprema "que todavía el Estado de Chile no se pone muy de acuerdo de cómo entenderse con la cultura mapuche, los jueces no son mapuche, entonces tienen que hacer el esfuerzo por incorporarse, etc.. Se trata de una relación "un poco precaria salvo casos especiales en que el tribunal está preparado, lo entiende bien y actúa en consecuencia”.

Finalmente, consultado sobre el cumplimiento de las decisiones de la Corte IDH, en particular por una condena a Chile, en que se hizo referencia al derecho fundamental a la identidad cultural ${ }^{142}$. El juez del máximo Tribunal dijo que "hemos reconocido que existe una Corte Interamericana y que sus decisiones son vinculantes... porque los países, Chile en este caso, lo dijo cuándo firmó y cuando adhirió al convenio [CADH]".

Una ministra de una corte de apelaciones que ejerce una de las regiones de alta presencia mapuche, no duda realzar las consecuencias del fallo en referencia de la Corte IDH:

"Entonces a partir de Norin Catriman [...], no podemos decir que el pueblo mapuche es un pueblo agresivo, no podemos decir que la zona mapuche es una zona de conflicto o una zona de guerra, hemos tenido que avanzar en esos estereotipos que hace 10 años atrás existían y formaban parte de decisiones judiciales, con lo terrible que significa incorporar no hechos ni derechos, sino que simplemente prejuicios"143.

142. Norín Catrimán y otros... vs. Chile (2014).

143. Entrevistada E9. 


\section{Análisis de las entrevistas:}

Estas distintas perspectivas permiten vincular las relaciones normativas con las dimensiones social y política de la vida en sociedad. Así, la cultura jurídica sigue apareciendo como un ente regulador de dichas dimensiones. Pero, al mismo tiempo, la cultura jurídica aparece como un punto de tensión y de crítica, como un vector de subjetivación de los actores jurídicos en su quehacer cotidiano.

Parte de los debates en los tribunales se relacionan con los principios y reglas internalizados en la cultura jurídica, como la imparcialidad del juez, el respeto de las garantías, en cuanto espacio de discursividad y de formación de un régimen de verdad (como "meta-cultura"144). De esta forma, la emergencia del derecho a la identidad cultural en Chile ha constituido un punto de tensión entre los actores jurídicos, al introducir un cambio de visión en sus formaciones, pero aún de avance inicial. Asimismo, coinciden los actores jurídicos entrevistados en que el derecho a la identidad cultural se ejerce, en gran medida, mediante el derecho a hablar su propia lengua, con el acompañamiento de facilitadores interculturales y, jurídicamente, al requerir la aplicación de la Ley Indígena y el Convenio 169 de la OIT. Ergo, se reconoce con la aplicación armónica de estos instrumentos en las sentencias.

Por su parte, la comprensión mayoritaria de los actores jurídicos descarta la "diferenciación entre personas de la etnia mapuche y personas chilenas"145. Tal posición, compartida en particular por jueces penales y fiscales, muestra una preponderancia en los procedimientos y criterios formales que invisibiliza las diferencias al omitir la presencia -en un sentido identitario cultural- de los mapuche en los tribunales por parte de quienes actúan desde los parámetros de la cultura dominante (como una "cosmovisión jerárquica" y un marco ideológico sostenido en "el carácter universal del sujeto de derecho moderno occidental"146). Así, abogados defensores, en particular aquellos que intervienen en causas contra personas mapuche, identifican las dificultades estructurales del Derecho chileno hegemónico, en especial para aplicar el Convenio 169 de la OIT, aunque, al mismo tiempo, admiten algunos avances que visualizan las potencialidades de generar cambios que este instrumento internacional contiene.

144. BRIONES (1998) pp. 6-7.

145. Entrevistado E7.

146. MARTINEZ (2019) p. 72. 
También se observa que las aperturas indicadas no son lineales, sino que están marcadas por los propios contextos y factores extrajurídicos que influyen en las decisiones, los elementos no normativos de la cultura jurídica, como la formación de los abogados y las prácticas subsistentes, que, tanto, dificultan esos procesos, como, al mismo tiempo, son los espacios más sensibles a la trasformación de la cultura jurídica.

\section{Pesquisas relevantes y conclusiones:}

La propuesta metodológica planteada operó bajo el presupuesto de que la comprensión del alcance del Derecho no puede sustentarse solo sobre su texto, porque debe tener en cuenta cómo opera el sistema normativo y, en especial, en base a qué factores deciden los tribunales. Por ello, para estudiar los impactos que genera el reconocimiento del derecho a la identidad cultural de pueblos indígenas y otros grupos, emergente y en acción, en la cultura jurídica chilena, consideramos dos perspectivas de trabajo: primero, avanzamos en una propuesta metodológica para el estudio de la cultura jurídica desde esta perspectiva; segundo, se estudió la cultura jurídica de los operadores de la administración de justicia, cuál es su percepción de las potenciales transformaciones que la emergencia del derecho a la identidad cultural ha podido tener en la cultura jurídica chilena.

Entonces, en el primer aspecto, metodológico, trabajamos desde el supuesto de que el estudio de los impactos de la cultura jurídica en los procesos de trasformación del Derecho exige el desarrollo de metodologías complejas, interdisciplinarias, adecuadas, creativas y dúctiles a los contextos identitarios, que superen las técnicas clásicas de la Ciencia del Derecho positivo, introduciendo enfoques aportados desde otras ciencias sociales. Para ello, la investigación aplicada contempló las siguientes dimensiones: (i) histórica, sociopolítica, contextual; (ii) normativa positiva (textual) en el nivel constitucional; (iii) normativa hermenéutica (jurisprudencial); y (iv) sociocultural (socio-etnográfica) en que se estudió la cultura jurídica interna, propiamente tal, desde el discurso y percepciones de los actores jurídicos.

Como conclusión general, podemos evidenciar que las controversias y litigios de derechos en que se disputan cuestiones radicadas en el derecho a la identidad cultural de pueblos indígenas y otros grupos: i) tienen un impacto en la transformación del Derecho y de la justicia; ii) se manifiestan, en gran parte, como transformaciones, "en tensión", de la cultura jurídica.

En relación a las respectivas dimensiones estudiadas. Primero, respecto del contexto histórico, social y cultural, global regional y nacional, constatamos que la cultura jurídica chilena se enmarca en un conjunto de interacciones socio-normativas "externas-internas" que han venido dando lugar a una nueva dogmática constitucional comparada que ha transitado desde las comprensiones asimilacionistas e integra- 
cionistas de la segunda mitad del siglo XX, presentes hasta fines de los años 80, hasta una visión constitucional "multicultural” y otra más reciente que se ha denominado "plurinacional"147. En este sentido, dijimos que los precedentes de la Corte IDH han reconocido y consolidado el derecho a la identidad cultural como una nueva categoría ius fundamental, a lo menos, en diálogo con las constituciones latinoamericanas. Y, consecuentemente, que existe un desplazamiento en etapa inicial, de la matriz democrática igualitaria constitucional clásica, hacia una nueva matriz democrática constitucional que denominamos "intercultural", que, a lo menos, impone una relectura de los alcances del paradigma igualitario dominante del constitucionalismo. Todo ello, habría venido permeando en diversas intensidades, de flujos y contraflujos, el marco normativo chileno y, en consecuencia, de forma inicial, aunque progresiva, la cultura jurídica chilena de jueces y otros actores.

En la dimensión normativa de la cultura jurídica, la CPR omite el reconocimiento de derechos de los pueblos indígenas y otros derechos culturales. No obstante, los precedentes de alcance constitucional han sido la vía para conformar un marco constitucional, normativo hermenéutico, de reconocimiento del derecho fundamental a la identidad cultural. Este desarrollo de precedentes no ha sido pacífico, por el contrario, se evidencian interpretaciones en tensión y disputas sobre el alcance del derecho a la identidad cultural, especialmente en el caso de los pueblos indígenas.

En relación a la dimensión jurisprudencial, la Corte Suprema viene aplicando sostenidamente en sus fallos el Convenio $\mathrm{N}^{\circ} 169$ de la OIT, a la luz de la apertura constitucional (artículo 5 inciso $2^{\circ}$ ) al Derecho Internacional de los derechos humanos.

Al efecto, la justificación constitucional predominante en las sentencias para el reconocimiento del derecho a la identidad cultural o de la protección de la diversidad cultural (según como se plantee), se ha sustentado, principalmente, en el carácter de "grupos vulnerables" de quienes han solicitado la tutela constitucional. Por ello, las cortes han destacado el deber que tiene el Estado, conforme el principio de igualdad, de generar acciones afirmativas de protección efectiva. Ello, si bien es un avance, constituye una comprensión limitada del derecho fundamental a la identidad cultural, en especial respecto de los pueblos indígenas y otros grupos titulares de derechos colectivos frente al Estado. Respecto de ellos, la vulnerabilidad radica, además de sus identidades culturales afectadas o en riesgo, en la imposibilidad de participar políticamente en la construcción del orden social ${ }^{148}$. En ese sentido, la vulnerabilidad, más bien, refiere a que no logran enfrentar en simetría los modos de ser hegemónicos y su

147. FIGUEIREDO (2019) pp. 733-734-751.

148. Un ejemplo claro de este fenómeno es la exclusión, aún subsistente -hasta la fecha de este artículo-, de los pueblos indígenas de Chile, como grupos con derecho a cupos reservados en el próximo proceso constituyente, si se aprueba esta opción en el plebiscito acordado al efecto. 
derecho a vivir conforme su cultura colisionan con otros derechos e intereses sociales, sostenidos por quienes sí tienen la capacidad de incidir en la toma de decisiones trascendentes para el devenir social. No es que los otros intereses no sean legítimos, que con frecuencia lo son, sino, de la capacidad de hacer valer los propios intereses (también legítimos) frente a los otros en el campo social y jurídico, para ser parte en la deliberación y toma de decisiones sobre ese conflicto de intereses (esto es muy frecuente cuando se disputa el uso de tierras, territorios indígenas o sus recursos naturales, para fines energéticos u otros estratégicos). Desde esta perspectiva, si bien se declaran comprensiones más o menos abiertas a la diversidad cultural, las culturas jurídicas también reflejan tensiones, avances y retrocesos, especialmente respecto de las comprensiones sociales y normativas sostenidas desde las posiciones de poder hegemónicas.

En resumen, por una parte, la jurisprudencia superior ha reconocido derechos de carácter cultural a los indígenas y se ha abierto un camino normativo de admisión del derecho fundamental a la identidad cultural, permeando la propia cultura jurídica chilena hegemónica hasta ahora predominante. Con ello, se puede observar que existe un marco de reconocimiento del derecho a la identidad cultural que ha generado un efecto de irradiación a otros derechos. Sin embargo, por otra, aún sigue siendo una cuestión disputada, sujeta a avances y retrocesos. Especialmente cuando se presentan colisiones con otros derechos e intereses sociales también legítimos.

La tensión indicada podría explicar que, si bien, en el ámbito de derechos territoriales y otras categorías, aunque formalmente los instrumentos internacionales han pasado a formar parte del ordenamiento jurídico chileno, la cultura jurídica de jueces y otros actores no los internalizó de forma inmediata, armónica, ni contundente.

Así, hoy se constata una fisura sobre las comprensiones marcadas por el positivismo jurídico, abaladas en los estándares internacionales de derechos humanos. En este sentido, se han podido constatar diversas prácticas, discursos y sentencias a nivel local que tienden a hacer pensar en la emergencia de cambios significativos orientados al reconocimiento del derecho a la identidad cultural. Mientras, al mismo tiempo, las visiones de carácter positivista o más cerradas al reconocimiento de las diferencias, aún son fuertes y de profunda incidencia en la jurisprudencia.

En consecuencia, observamos lo que hemos llamado un "contra flujo" socionormativo, porque, por una parte, el marco jurídico se ha abierto al Derecho Internacional de los derechos humanos, a la valoración de la cultura y el reconocimiento de la diferencia. Pero, por otra, las comprensiones positivistas y monoculturales del Derecho mantienen alta incidencia en los procesos decisorios. En este sentido, se constata en las sentencias, por ejemplo, una técnica argumentativa en que, primero, en abstracto, se reconocen la existencia de un bien jurídico que requiere tutela y reconocen el respectivo derecho fundamental que debe ser resguardado. Pero, acto seguido, confor- 
me los supuestos de hecho o la hipótesis argumental aplicada al caso en concreto, se descarta la aplicabilidad del amparo jurisdiccional en ese caso. Con ello, en definitiva, se "cumple" en términos declarativos, pero se desprotege a la persona o al grupo, apartando la decisión de la justicia material en el caso. Estas estrategias argumentales quedaron en evidencia cuando los jueces frente a supuestos de facto similares o unos mismos bienes jurídicos afectados, resolvieron en concreto de forma contradictoria. Nuestra explicación para estos casos (y he aquí la ventaja de la metodología interdisciplinaria formulada: contextual, normativa positiva, hermenéutica jurisprudencial y socioetnográfica), no radica solo en una cuestión de textos constitucionales o de tratados internacionales (cuya aplicación progresiva vimos), tampoco en una estricta técnica hermenéutica o argumental "apegada a Derecho". Sino, en parte relevante, en los factores de la decisión arraigados en la cultura jurídica de los sentenciadores.

La emergencia del derecho a la identidad cultural en Chile constituye un punto de tensión entre los actores jurídicos que refleja cuestiones no resueltas en nuestra sociedad, al introducir un cambio de paradigma en la comprensión sobre el derecho a la diferencia y el respecto de la cultura y las culturas, que colisiona con el paradigma igualitario que históricamente ha invisibilizado a pueblos indígenas y otros grupos. Al mismo tiempo, los actores jurídicos perciben un cambio, en especial a la luz de la aplicación del Convenio 169 de la OIT y otros tratados de derechos humanos, que ha implicado avances en la afirmación del derecho a la identidad cultural, aunque, también dan cuenta de las dinámicas subsistentes desde la mirada positivista hegemónica. Por ello, podemos decir que la cultura jurídica chilena, en relación al derecho a la identidad cultural, muestra "fisuras", no lineales y en tensión, determinadas por los contextos y factores extrajurídicos que influyen en las decisiones judiciales. Se trata, precisamente, de aquellos componentes no normativos de la cultura jurídica, como la formación de los abogados, sus percepciones, representaciones, preconcepciones, con las respectivas prácticas y discursos, que -en un "contra flujo"- tanto resisten los cambios, como son el objeto mismo de la trasformación de la cultura jurídica chilena.

\section{Referencias bibliográficas}

AGUAS, Javier y NAHUELPAN, Héctor (2019): “Los límites del reconocimiento indígena en chile neoliberal. La implementación del Convenio 169 de la OIT desde la perspectiva de dirigentes mapuche williche". Revista CUSHO, año 29, $\mathrm{N}^{\circ} 1$, pp. 108-130.

AGUILAR, Gonzalo (2010): "Emergencia de un derecho constitucional común en materia de pueblos indígenas", En VON BOGDANDY, Armin; FERRER MAC-GREGOR y Eduardo, MORALES-ANZIONATTI, Mariela (Eds.), La justicia constitucional y su internacionalización. ¿Hacia un Ius Constitucionale Commune en América Latina? (México, UNAM, MPI, IIADC), Tomo II, pp. 3-84. 
AGUILAR, Gonzalo y NOGUEIRA, Humberto (2016): "El principio favor persona en el derecho internacional y en el derecho interno como regla de interpretación y de preferencia normativa". Revista de Derecho Público, año 84, No 1, pp. 13-43.

AYLWIN, José, MEZA-LOPEHANDÍA, Matías y YAÑZ, Nancy (2013): Los pueblos indígenas y el derecho (Santiago, LOM, Observatorio Ciudadano).

AZÓCAR, María José (2018): “Cómo se construye la experticia judicial?: Una etnografía judicial en Tribunales de familia de Santiago de Chile". Revista de derecho (Valdivia), año 31, $\mathrm{N}^{\circ}$ 2, pp. 9-27.

BARRIENTOS PARDO, Ignacio (2008): "Licitud del porte y uso de la hoja de coca”. Política Criminal, N 5, 2008, A 4-5: pp. 1-30.

BENGOA, José (2000a): La emergencia indígena en América Latina (Santiago, Fondo de Cultura Económica).

BENGOA (2000.b). Historia del Pueblo Mapuche (Santiago, LOM).

BENGOA (2007). Historia de un Conflicto (Santiago, Planeta).

BERHO, Marcelo, CASTRO, Paulo y LE BONNIEC, Fabien (2018): "La Pericia Antropológica en la Araucanía de Chile. Entre Teorías y Prácticas, 2003 2014". Antropologías Del Sur, año 16, N³, pp. 107-126.

BINDER, Alberto (2005): "Los oficios del jurista: la fragmentación de la profesión jurídica y la uniformidad de la carrera judicial". Academia: revista sobre enseñanza del derecho de Buenos Aires, №5, pp. 85-116.

BINDER, Alberto (2004): Introducción al Derecho Penal (Buenos Aires, Ad-hoc) pp. 272-274.

BOGDANDY, Armin von, MORALES ANTONIAZZI, Mariela y FERRER MACGREGOR, Eduardo (coords.) (2017): IUS CONSTITUTIONALE COMMUNE en América Latina: Textos Básicos para su Comprensión (Querétaro, Instituto de Estudios Constitucionales del Estado de Querétaro, Max Planck Institute for Comparative Public Law and International Law).

BOLADOS, Paola y BOCCARA, Guillaume (2014): “Du néolibéralisme multiculturel aux mobilisations post-multiculturelles". Actuel Marx, año 56, N², pp. 74-84.

BOURDIEU, Pierre (1991): “Les juristes, gardiens de l'hypocrisie collective”. En CHAZEL, François, COMMAILLE, Jacques (Eds.), Normes juridiques et régulation sociale (Paris, LGDJ, collection Droit et société). 
BRIONES, Claudia (1998): (Meta)cultura del estado-nación y estado de la (meta) cultura (Brasília, Série Antropologia 244). Disponible en http://www.dan. unb.br/images/doc/Serie244empdf.pdf [Fecha de la consulta: 30.04.2020].

BUSTOS, Rafael (2012): Pluralismo constitucional y diálogo jurisprudencial (México, Porrúa).

BUSTOS, Rafael (2005): La Constitución red: un estudio sobre supraestatalidady constitución (Bilbao, Ed. Instituto Vasco de Administración Pública).

CANALES, Manuel (2006): Metodologías de la investigación social. Introducción a los oficios (Santiago, LOM, CHARUDEAU).

CARMONA, Cristóbal (2013): "La aplicación del derecho a consulta del Convenio 169 de la OIT en Chile: hacia una definición de su contenido sustantivo: afectación e instituciones representativas". En MIRANDA, Ricardo, CARMONA, Cristóbal, Tesis (maestría) sobre Pueblos Indígenas, Vol. III, Colección Tesis de Maestría U. Nacional San Martín de Buenos Aires (Buenos Aires, Universidad Nacional de San Martín, CIEP).

CARMONA, Cristóbal (2015): "Hacia una comprensión 'trágica' de los conflictos multiculturales: acuerdos reparatorios, IF y derecho propio indígena". Revista Chilena de Derecho, año 42, N³, pp. 975-1001.

CASTRO, Milka y VERGARA, Juan (Editores) (2009). Jurisprudencia indigena. Cosmovisión y legislación (Santiago, U. de Chile).

CHARAUDEAU, Patrick (2006): Un modèle socio-communicationnel du discours. Entre situation de communication et stratégies d'individuation. Médias et Culture. Discours, outils de communication, pratiques: quelle(s) pragmatique(s)? (Paris, L'Harmattan).

CENTRO DE ESTUDIOS DE JUSTICIA DE LAS AMÉRICAS -CEJA- (2015): Reforma procesal penal y pueblos indigenas. Disponible en: http://biblioteca.cejamericas.org/bitstream/handle/2015/5129/RPPYPUEBLOSINDIGENAS_IMARENSI.pdf?sequence $=1 \&$ isAllowed $=y$ [Fecha de la consulta: 30.04.2020].

COMISIÓN INTERAMERICANA DE DERECHOS HUMANOS -CIDH- Informe Nº138/18, Petición 687-11, "Gabriela Blas Blas y su hija C.B.B., Chile., de 21 de Noviembre de 2018. Disponible en: https://www.oas.org/es/cidh/decisiones/2018/CHSA687-11ES.pdf [Fecha de la consulta: 30.04.2020].

CLAROS, Luis y VIAÑA, Jorge (2009): "La interculturalidad como lucha contrahegemónica. Fundamentos no relativistas para una crítica de la de la cultura". En VVAA, Interculturalidad crítica y descolonización Fundamentos para el debate (La Paz, Convenio Andrés Bello) pp. 117-118. 
CLOUD, Leslie y LE BONNIEC, Fabien (2019): "Dynamiques actuelles de criminalisation et de judiciarisation des droits autochtones au Chili". En BELLIER, Irène, HAYS, Jennifer (eds.), Echelles de gouvernance et peuples autochtones : de nouveaux droits ou la répétition des erreurs du passé ? (Paris, L'Harmattan) pp. 235-254.

CLOUD, Leslie y LE BONNIEC, Fabien (2012): "Entre logiques d'Etat et autochtonie: dynamiques de la territorialité mapuche à l'heure du droit à l'autodétermination des Peuples Autochtones". QuAderns-e de l'Institut Catala d'Antropologia, año $17, \mathrm{~N}^{\circ} 1$, pp. 25-43.

COUSO, Javier (2013): "Mapuches y Derecho Penal". En OLEA RODRÍGUEZ, Helena (ed), Derecho y Pueblo Mapuche: aportes para la discusión (Santiago, Centro de Derechos Humanos UDP) pp. 155-214.

COUSO, Javier y HILBINK, Lisa (2011): "From Quietism to Incipient Activism: The Institutional and Ideological Roots of Rights Adjudication in Chile". In HELMKE, Gretchen, RÍOS-FIGUEROA, Julio (Eds.), Courts in Latin America (Cambridge, Cambridge University Press) pp. 99-127.

CURY, Enrique (2005): Derecho Penal. Parte General (Santiago, Ediciones Universidad Católica de Chile).

DE LA SIERR, Susana (2004): Una metodología para el Derecho Comparado europeo. Derecho Público Comparado y Derecho Administrativo Europeo (Madrid, Thomson, Civitas, Arazandi).

DE MAGLIE, Cristina (2012): Los delitos culturalmente motivados ideologías y modelos penales (Madrid, Marcial Pons).

DEFENSORÍA PENAL PÚBLICA -DPP- (2017): $4^{\circ}$ informe de jurisprudencia sobre defensa penal de imputados indigenas (Santiago, Departamento de Estudios y Proyectos, Unidad de Defensa Penal Juvenil y Defensas Especializadas).

DEFENSORÍA PENAL PÚBLICA -DPP- (2013): $2^{\circ}$ Informe de jurisprudencia sobre defensa penal de imputados indigenas (Santiago, Departamento de Estudios y Proyectos, Unidad de Defensa Penal Juvenil y Defensas Especializadas).

DEWEY, John (2011): La formation des valeurs (Paris, La Découverte).

DUCONGE, Giselle y LUBE, Menara (2014): "Afroariqueños: configuraciones de un proceso histórico de presencia". Estudios Atacameños, № 49, pp. 129 $-151$.

DUPRET, Baudouin (2006): Droits et sciences sociales (Paris, Armand Colin).

DUPRET, Baudouin (2010): "Droit et sciences sociales. Pour une respécification praxéologique”. Droit et société, año 2, №75, pp. 315-335. 
ESPINOZA COLLAO, Álvaro (2017): "El reconocimiento del derecho consuetudinario indígena como derechos humanos: su estado en el derecho chileno moderno". Cadernos de Dereito Actual, № 8, pp. 413-437.

FAUNDES, Juan Jorge (2020a): "El derecho fundamental a la identidad cultural de los pueblos indígenas, configuración conforme el derecho internacional y perspectivas de su recepción en Chile". Ius et Praxis, año 26, N¹, pp. 77-100.

FAUNDES, Juan Jorge (2020b): “Consulta indigena y centrales de generación hidroeléctrica de menos de 3MW: desregulación riesgosa, a la luz del derecho fundamental a la identidad cultural de los pueblos indigenas". En BOZZO, Sebastián, REMESEIRO, Rebeca y ESIS, Ivette (Edits.). Memorias III Congreso Internacional de Regulación y Consumo (Santiago, RIL, Universidad Autónoma de Chile) pp. 359-398.

FAUNDES, Juan Jorge (2020c): Horizontes constituyentes. Reconocimiento de los pueblos indigenas en América Latina. Los casos de Chile y Bolivia (Curitiba, Appris).

FAUNDES, Juan Jorge (2019a): "Derecho fundamental a la identidad cultural de los pueblos indígenas: un nuevo paradigma en la defensa penal indígena en Chile frente al Estado de Derecho hegemónico". Revista Izquierdas, №45, febrero 2019, pp. 51-78.

FAUNDES, Juan Jorge. (2019b): "El derecho fundamental a la identidad cultural de los pueblos indígenas: un derecho-matriz y filtro hermenéutico para las constituciones de América Latina: la justificación". Revista Brasileira de Políticas Públicas, año 9, №2, pp. 513-525.

FAUNDES, Juan Jorge (2017): "Derechos humanos y el reconocimiento de la identidad cultural de los pueblos indígenas en América Latina, en la perspectiva crítica del descentramiento intercultural". En OLVERA, Jorge, OLVERA, Julio, GUERRERO, Ana Luisa (coords.), Los pueblos originarios en los debates actuales de los derechos humanos (México, UNAM, CIAC): pp. 39-60.

FAUNDES, Juan Jorge (2015): “Convenio $N^{\circ} 169$ de la OIT en la Jurisprudencia de la Excelentísima Corte Suprema en Chile. Tendencias y debates en materia de propiedad y derecho al Territorio". En Colecciones Jurídicas de la Corte Suprema. Disponible en: http://decs.pjud.cl/documentos/academicos/Tendencias_Jurisprudenciales_Convenio169.pdf [Fecha de la consulta: 30.04.2020].

FAUNDES, Juan Jorge (2013): "Integración regional, reformas a la justicia y respeto del estándar internacional de derechos humanos en los procesos penales seguidos contra indigenas movilizados socialmente". En ÁLVAREZ, Mario, CIPPITANI, Roberto (coords.). Derechos Individuales e Integración Regional (Antología) (Roma-Perugia-México, Istituto per gli Studi Economici e Giuridici -ISEG-): pp. 417-476. 
FAUNDES, Juan Jorge y LE BONNIEC, Fabien, (2020): Comparando la cultura jurídica desde el derecho a la identidad cultural en Brasil y Chile". Brazilian Journal Of International Law, año 17, $\mathrm{N}^{\circ} 1$, Dossier especial Comparative Law and its protagonists: what use, for what purpose, with which methods?

FAUNDES Juan Jorge y RAMÍREZ Silvina (Editores.) (2020): Derecho fundamental a la identidad cultural, abordajes plurales desde América Latina (Santiago, Universidad Autónoma de Chile), en prensa.

FAUNDES, Juan Jorge y VALLEJOS, Liz (2020): "El derecho fundamental a la identidad cultural de los pueblos indígenas, titulares, naturaleza, contenido $y$ alcances, desde la jurisprudencia de la Corte Interamericana de Derechos Humanos". En FAUNDES Juan Jorge, RAMÍREZ Silvina (Editores.), Derecho fundamental a la identidad cultural, abordajes plurales desde América Latina (Santiago, Universidad Autónoma de Chile), en prensa.

FERNÁNDEZ MÍGUEZ, Sheila (2018): La violencia machista en Chile: Una visión desde el Derecho Penal y la Justicia Mapuche (Tesis de doctorado, Universidade de A Coruña y Universidad Autónoma de Chile).

FERNÁNDEZ, Sheila y FAUNDES Juan Jorge (2019): “Emergencia de las mujeres indígenas en América latina. Debates sobre género, etnicidad e identidad cultural”. Revista Chilena de Derecho y Ciencia Política, año 2, N 10, pp. 53-96.

FIGUEIREDO, Marcelo (2019): “Constitucionalismo Latino-Americano e Cultura Constitucional". En VON BOGDANDY, Armin, PIOVESAN, Flávia, MORALES ANTONIAZZI, Mariela (Coords.), Constitucionalismo Transformador, Inclusacao e direitos coaciais. Desafíos do IUS CONSTITUCIONALE COMMUNE Latino-Americano à la luz do Direito Econômico Internacional (Salvador Bahía, EDITORA JusPODIVM): pp. 725-752.

FORNET-BETANCOURT, Raúl (2011): La Filosofía Intercultural y la dinámica del reconocimiento (Temuco: Ediciones Universidad Católica de Temuco).

FRIEDMAN, Lawrence (1975): The Legal System. A Social Science Perspective (New York, Russell Sage Foundation).

FUENZALIDA, Edmundo (2000): Cultura jurídica externa e interna en el Chile finisecular: ¿Convergencia o divergencia?. En: Anuario de filosofía jurídica y social. Sociedad chilena de filosofía jurídica y social. Año, $N^{\circ}$ 20, pp 473-483.

GARCÍA ROCA, Javier, FERNÁNDEZ SÁNCHEZ, Pablo, SANTOLAYA, Pablo, CANOSA, Raúl (2015): El diálogo entre los sistemas europeo y americano de Derechos Humanos, Segunda edición (Lima, ECB editores).

GONZÁLEZ, Claudio (2018): Gestión, gerencialismo y sistema penal (Buenos Aires, Bdef). 
GREEN, Francisca (2015): "Los afrodescendientes en Chile y en la región de Arica Parinacota". Minuta, Biblioteca del Congreso Nacional. Disponible en: https://www.camara.cl/verDoc.aspx?prmTIPO=DOCUMENTOCOMUNIC ACIONCUENTA\&prmID=6407 [Fecha de la consulta: 08.06.2020].

HENRÍQUEZ, Miriam y MORALES, Mariela (2017): El control de convencionalidad: un balance comparado a 10 Años de Almonacid Arellano vs. Chile (Santiago, DER Ediciones).

HERSANT, Jeanne (2019): "Mérite et bienveillance: faire carrière dans l'administration judiciaire au Chili (1974-2016)". Critique Internationale, año 82, $\mathrm{N}^{\circ} 1$, pp. 117-136.

HUALPA, Eduardo (2014): Derechos Constitucionales de los Pueblos Indigenas (Buenos Aires, Ad-Hoc).

INSTITUTO NACIONAL DE ESTADÍSTICAS -INE- (2014): "Primera Encuesta de Caracterización de la Población Afrodescendiente de la Región de Arica y Parinacota. Febrero 2014". Disponible en: https://www.ine.cl/docs/defaultsource/etnias/publicaciones-y-anuarios/encuesta-de-caracterizacion-dela-poblacion-afrodescendiente-2013/presentaci\%C3\%B3n-primera-encuesta-de-caracterizaci\%C3\%B3n-de-la-poblaci\%C3\%B3n-afrodescendiente. pdf?sfvrsn=d5ad69f4_4 [Fecha de la consulta: 08.06.2020].

INSTITUTO NACIONAL DE ESTADÍSTICAS -INE- (2018): "Síntesis de resultados Censo 2017” Disponible en: https://www.censo2017.cl/descargas/home/ sintesis-de-resultados-censo2017.pdf [Fecha de la consulta: 30.04.2020].

INSTITUTO NACIONAL DE ESTADÍSTICAS -INE-, MIDEPLAN-BID (2005): "Estadísticas sociales de los pueblos indígenas en Chile. Censo 2002". Disponible en: https://www.ine.cl/docs/default-source/etnias/publicaciones$\mathrm{y}$-anuarios/estadisticas-sociales-pueblos-indigenas-en-chile-censo-2002/ estad\%C3\%ADsticas-sociales-pueblos-ind\%C3\%ADgenas-en-chile-censo2002f49639a0fc86495aaee213280de26250.pdf?sfvrsn=518d27c4_4 [Fecha de la consulta: 30.04.2020].

KALINSKY, Beatriz (2000): Justicia, Cultura y Derecho Penal (Buenos Aires, AdHoc S.R.L).

KOSVSKY, Fernando (2014): "Desconocimiento territorial y usurpación en Río Negro". En DA ROCHA, Joaquín, DE LUCA, Javier (Coordindores), La Justicia penal en las comunidades originarias (Buenos Aires, Ad-Hoc), pp. 169190.

LATOUR, Bruno (2002): La fabrique du droit. Une ethnographie du Conseil d'État (Paris, La Découverte). 
LE BONNIEC, Fabien (2018a): "Juridicité autochtone et différence culturelle. Quand les juges débattent de la culture dans des affaires de violences familiales en contexte communautaire mapuche (Chili)". Ethnologie française, año 169, $\mathrm{N}^{\circ} 1$, pp. 141-142.

LE BONNIEC, Fabien (2018b): "Interrogantes en torno a la emergencia del peritaje antropológico en las cortes de justicia del sur de Chile". En CARRASCO, Morita; LUXARDO, Natalia (Eds.), El orden cuestionado. Lecturas de antropología jurídica (Buenos Aires, UNSAM Edita) pp. 117-130.

LÓPEZ MEDINA, Rocío del Carmen (2015): "Cultura jurídica”, Eunomía. Revista en Cultura de la Legalidad, No. 7, septiembre 2014 - febrero 2015, pp. 229-235.

LÓPEZ, Ricardo, MOHR, Tania (2014): "Susceptibilidad de afectación directa en la consulta previa del Convenio 169. Análisis de Normas Previstas y de su trato en la Jurisprudencia. ¿Una cuestión de derecho?”. Revista de Derecho (Valdivia), año XXVII-N ${ }^{\circ} 1$-Julio 2014, pp. 105-126.

LUHMANN, Niklas (2002): El derecho de la sociedad (México, Universidad Iberoamericana).

MARIÑO, Fernando (2001): "Introducción: aproximación a la noción de persona y grupo vulnerable en el derecho europeo". En MARINO, Fernando, FERNÁNDEZ, Carlos, (Coords.), La protección de las personas y grupos vulnerables em el derecho europeo (Madrid, Universidad Carlos III de Madrid), pp. 19-26.

MARTÍNEZ, Héctor Wladimir (2019): Producción de la diferencia en los espacios de justicia: una aproximación etnográfica al proceso de atención de usuarios mapuche en tribunales de justicia de La Araucanía. Actividad Formativa Equivalente para optar al grado de Magíster en Antropología (Temuco, Universidad Católica de Temuco).

MELLO, Patrícia Perrone Campos (2015): Nos Bastidores do Supremo Tribunal Federal (Rio de Janeiro, Forense).

MELLO, Patrícia Perrone Campos (2019a): "Comportamiento judicial estratégico: el caso del Supremo Tribunal Federal de Brasil". Revista Chilena de Derecho y Ciencia Política, año 10, No1, pp. 168-195.

MELLO, Patrícia Perrone Campos (2019b): “Constitucionalismo, transformação e resiliência democrática no Brasil: o Ius Constitucionale Commune na América Latina tem uma contribuição a oferecer? Revista Brasileira de Políticas Públicas, año 9, N², pp. 253-285. 
MELLO, Patricia Perrone Campos (2020): "Proteção à vulnerabilidade na jurisprudência do Supremo Tribunal Federal do Brasil: a defesa da população LGBTI+". Revista da AGU, año 19, N¹, pp. 17-43.

MELLO, Patrícia Perrone Campos, LACERDA, Clara (2020): "El derecho fundamental a la identidad cultural y el constitucionalismo en red en la jurisprudencia del supremo tribunal federal de Brasil". En FAUNDES Juan Jorge, RAMÍREZ Silvina (Edts.), Derecho fundamental a la identidad cultural, abordajes plurales desde América Latina (Santiago, Universidad Autónoma de Chile) en prensa.

MELLO, Patrícia Perrone Campos, FAUNDES, Juan Jorge (2020): “Constitucionalismo em rede: o direito à identidade cultural dos povos indígenas como filtro hermenêutico para tutela da tradicionalidade da ocupação da terra". En ROSSITO, Flávia, SILVA, Liana, TÁRREGA, M.C.B., BOTELHO, Tiago, Quilombolas e outros povos tradicionais (Curitiba: CEPEDIS -Centro de Pesquisa e Extensâo em Direito Socioambiental-) pp. 317-339.

MILlamÁN, Sergio (2019): "Consulta indígena, Pueblo Mapuche, territorios y evaluación medioambiental", Documento de trabajo ICSO - No 52/ 2019. Serie Laboratorio Constitucional (Santiago, Instituto de Investigación en Ciencias Sociales, UDP) Disponible en: https://www.icso.cl/wpcontent/uploads/2019/03/ICSO_DT_52_Millaman.pdf [fecha de consulta: 30.04.2020].

MIRANDA, Fabiola y GAC, Daniella (2020): "Etnografía y políticas públicas en materia de justicia y violencia contra las mujeres en Chile." Polis. Revista latinoamericana, año 19. $\mathrm{N}^{\circ} 55$, pp. 1-17.

MORALES ANTONIAZZI, Mariela (2016): “O Estado Aberto: Objetivo do Ius Constitucionale Commune". Em BOGDANDY, Armin von, MORALES ANTONIAZZI, Mariela, PIOVESAN, Flávia (Coord). IUS CONSTITUCIONALE COMMUNE NA América Latina: Marco conceptual (Curitiba: Juruá), Volumen 1, pp. 53-74.

MONTORO, Alberto (2007): "El funcionalismo en el Derecho: Notas sobre N. Luhmann y G. Jakobs. Anuario de Derechos Humanos". Anuario de Derechos Humanos Nueva Época, año 8, pp. 365-374.

NASH, Claudio, LAGOS, Catalina, NÚÑEZ, Constanza, BUSTAMANTE, Minda y LABRA, Consuelo (2013): Erradicación de la Violencia Contra las Mujeres en las Américas: pautas para decidir la procedencia de acuerdos reparatorios (Santiago, Centro de Derechos Humanos, Universidad de Chile).

NELKEN, David (Ed.) (1997): Comparing legal cultures (Vermonth, Darmonuth Publishing Company). 
NELKEN, David (2017): "Defining and using the Concept of juridica Culture". En ADAMS, Maurice, HUSA, Jaakko, ODERKERK, Marieke (ed.), Comparative Law Methodology (Massachusets, EE Elgar) Volume II, pp. 332-355.

NOGUEIRA, Humberto y AGUILAR, Gonzalo (Coord.) (2017): Control de convencionalidad, corpus iuris y ius commune interamericano (Santiago, Editorial triángulo, $\mathrm{CECOCH}$ ).

PAILLACURA, Darwin (2019): La cultura jurídica chilena frente al derecho fundamental a la identidad cultural de los pueblos indígenas: un análisis del campo jurídico de la Araucanía (Tesis para optar al grado de Licenciado en Ciencias Jurídicas, Universidad Católica de Temuco).

PALMA, Rosario y SANDRINI, Renata (2014): "Mujer mapuche y retos de la justicia intercultural: aplicación del derecho propio indígena en delitos de violencia intrafamiliar". Anuario de Derechos Humanos, No10, pp. 151-161.

PÁSARA, Luis (ed.) (2007): Los actores de la justicia Latinoamericana (Salamanca, Universidad de Salamanca).

PIZZOLO, Calogero (2017): Comunidad de intérpretes finales. Relación entre tribunales supranacionales, constitucionales y supremos. El diálogo judicial (Buenos Aires, ASTREA).

POU, Francisca (2011): "Justicia constitucional y protección de derechos en América Latina: el debate sobre la regionalización del activismo”. En RODRÍGUEZ, Cesar (ed.), El derecho en América Latina. Un mapa para el pensamiento jurídico del siglo XXI (Buenos Aires, Siglo XXI) pp. 231-250.

RAMÍREZ, Silvina (2015): Matriz constitucional, Estado intercultural y derechos de los pueblos indígenas (Buenos Aires, Ad-Hoc).

RAMÍREZ, Silvina (2010): "Siete problemas del Nuevo Constitucionalismo indígena”. En YRIGOREN, Raquel (ed.) Pueblos Indígenas. Constituciones y reformas políticas en América Latina (Lima, ILSA, INESC, IIDS).

RIBOTTA, Silvina (2012): "Reglas de Brasilia sobre acceso a la justicia de las personas en condición de vulnerabilidad. Vulnerabilidad, pobreza y acceso a la justicia”. Revista Electrónica Iberoamericana, año 6, №2, pp. 1-37.

RODRÍGUEZ, César (2011): "Navegando la globalización: un mapamundi para el estudio y la práctica del derecho en América Latina”. En RODRÍGUEZ, César (Coord.), El derecho en América Latina. Un mapa para el pensamiento jurídico del siglo XXI (Buenos Aires, Siglo XXI) pp. 69-84.

ROJAS, Daniel (2014): Análisis conceptual del derecho a la tierra de los pueblos indígenas según el derecho internacional (Tesis de grado, Facultad de Derecho, P.U. C. Valparaíso, Santiago, INDH). 
SALAS, Ricardo (2003): Ética Intercultural (Santiago, Ediciones UCSH).

SALAS, Ricardo, FAUNDES, Juan Jorge (2018): "Justicia e interculturalidad. Conflictos y desafíos jurídico-políticos en el Wallmapu (Chile)". En LEDESMA Marianela (coord.), Justicia e Interculturalidad, análisis y pensamiento plural en América y Europa (Lima, CEC - Tribunal Constitucional del Perú) pp. 693737.

SANTOS, Boaventura de Sousa (1995): Toward a new common sense: Law, science and politics in the paradigmatic transition (New York, Routledge).

SARMENTO, Daniel (2010): Direitos Fundamentais e Relações Privadas. 2. Ed (Rio de Janeiro, Editora Lumen Juris).

SIEDER, Rachel (2011): "Pueblos indígenas y derecho(s) en América Latina". En RODRÍGUEZ, César (ed), El derecho en América Latina. Un mapa para el pensamiento jurídico del siglo XXI (Buenos Aires, Siglo XXI) pp. 302-321.

SIEMS, Mathias (2018): Comparative Law (Law in context). Second edition (Cambridge, Cambridge University Press).

SOUSA, Mariana (2007): "Breve panorama de la reforma judicial en América Latina: objetivos, desafíos y resultados". En LORA, Eduardo (ed.), El estado de las reformas del Estado en América Latina (Bogotá, Banco Mundial, Mayol Ediciones) pp. 99-137.

SOUZA NETO, Cláudio Pereira de, SARMENTO, Daniel (2014): Direito Constitucional - teoria história e métodos de trabalho. 2da. Ed. (Belo Horizonte, Editora Fórum).

SQUELLA, Agustín (1988): La cultura jurídica chilena (Santiago de Chile, Corporación de promoción universitaria).

TARELLO, Giovanni (1988): Cultura giuridica e politica del diritto (Bologna, Il Mulino).

UC TEMUCO y DPP (2017): "Modelo de Gestión para el Peritage Antropológico" -MoGPA-.

VALENZUELA, Mylene y OLIVA, Sergio (2018): Recopilación de legislación indigena 1813-2017 (Santiago, Librotecnia).

VILLEGAS, Myrna y MELLA, Eduardo (2017): Cuando la costumbre se convierte en ley. La cuestión penal y la pervivencia de los sistemas sancionatorios indígenas en Chile (Santiago, LOM).

YRIGOYEN, Raquel (2011): "El horizonte del constitucionalismo pluralista: del multiculturalismo a la descolonización”. En RODRÍGUEZ, Cesar (coord.), El derecho en América Latina. Un mapa para el pensamiento jurídico del siglo XXI (Buenos Aires, Siglo XXI) pp. 139-159. 
YRIGOYEN, Raquel (2012): "Pluralismo jurídico y jurisdicción indígena en el horizonte del constitucionalismo pluralista”. En AHRENS, Helen (ed.), El Estado de derecho hoy en América Latina: libro homenaje a Horst Schönbohm (Montevideo, Editorial Konrad-Adenauer-Stiftung E.V.) pp. 171-194.

\section{Jurisprudencia:}

"Alejandro Papic Domínguez con Comunidad Indígena Aymara Chusmiza y Usmagama" (2009): Corte Suprema, Rol 2840-2008, 25 noviembre 2009 (Recurso de casación forma y fondo).

“Atala Riffo y Niñas vs. Chile” (2012): Corte Interamericana de Derechos Humanos, 24 febrero 2012 (Reparaciones y costas).

“Caso Aloeboetoe y otros vs. Surinam” (1993): Corte Interamericana de Derechos Humanos, 10 septiembre de 1993 (Reparaciones y Costas).

"Caso Comunidad Garífuna de Punta Piedra y sus miembros vs. Honduras" (2015): Corte Interamericana de Derechos Humanos, 8 octubre de 2015 (Excepciones Preliminares, Fondo, Reparaciones y Costas).

"Caso comunidades indígenas miembros de la asociación Lhaka Honhat (nuestra tierra) vs. Argentina" (2020): Corte Interamericana de Derechos Humanos, 6 febrero 2020 (fondo, reparaciones y costas).

"Caso de la Comunidad Indígena Sawhoyamaxa Vs. Paraguay" (2006): Corte Interamericana de Derechos Humanos, 29 de marzo de 2006.

"Caso de la Comunidad Moiwana vs. Suriname” (2005): Corte Interamericana de Derechos Humanos, 15 junio de 2005 (Excepciones Preliminares, Fondo, reparaciones y Costas).

"Caso Norín Catrimán y otros (dirigentes, miembros y activista del pueblo indígena mapuche) vs. Chile" (2014): Corte Interamericana de Derechos Humanos, 29 de mayo de 2014 (fondo, reparaciones y costas).

“Caso del Pueblo Indígena Kichwa de Sarayaku vs. Ecuador" (2012): Corte Interamericana de Derechos Humanos, 27 junio 2012 (Reparaciones y costas).

“Caso del Pueblo Saramaka vs. Surinam" (2007): Corte Interamericana de Derechos Humanos, 28 noviembre de 2007 (Excepciones Preliminares, Fondo, Reparaciones y Costas).

"Comunidad indígena antu lafquen de huentetique contra Comision Regional del Medio Ambiente Región de los Lagos" (caso Parque Eólico Chiloé) (2012): Corte Suprema, Rol 10.090-2011, 22 marzo 2012 (Recurso de protección).

“Comunidad indígena Entuco contra Municipalidad de Padre las Casas" (2016): Corte Suprema, Rol 36.728-2015, 4 abril 2016. 
"Contra/ José Patricio Maripil Porteño y otros" ("Malón de Caiñicu”) (2012): Corte Suprema, Rol 2683-10, 26 enero de 2012 (Casación fondo). Corte de Apelaciones de Concepción, 9 febrero de 2010; Juzgado de Letras de Santa Bárbara, Rol 2.683-10, 15 marzo de 2005.

"Curin Tromo Celmira con Bosques Arauco S.A." (2009): Corte de Apelaciones de Temuco, Rol 1.864-2008, 6 de enero de 2009.

"Herminia Toroco Herrera y Amelia Mamani Charcas con Sociedad Inversiones e Inmobiliaria Villa Nueva S.A." (2013): Corte Suprema, Rol 3010-2013, 26 septiembre 2013 (Recurso de protección).

“Ingeborg Rendel Augant con Comunidad Indígena José Gineo Nanco" (2010): Corte Suprema, Rol 7.655-2008, 29 septiembre de 2010 (Casación fondo). Corte Apelaciones de Temuco, Rol 2162-2007, 5 noviembre 2008; Segundo Juzgado Civil de Temuco, Rol 60.889-2002, 3 septiembre 2008.

"Juan Segundo Pichún contra Sebastián Pinera Echeñique" (2017): Corte Suprema, Rol 41.865-2017, 26 diciembre 2017 (Recurso de protección).

"Linconao Francisca con Forestal Palermo" (2009): Corte de Apelaciones de Temuco, Rol 1773-2008, 16 septiembre 2009. Corte Suprema, Rol 7287-2009, 30 noviembre 2009.

"Maria Isabel Jamerne Jamerne Contra Marta Angelina Coliñanco Huechulef" (2013): Corte de Apelaciones de Temuco, Rol 130-2013, 1 abril 2013 (Recurso de nulidade). Corte Suprema, Rol 2145-1316, 16 mayo 2013 (Queja). Juzgado de Garantía de Villarrica, RUC 1010033388-6, RIT 1494-2010, 9 febrero de 2013 (Sentencia RPP).

“Norín Catriman y otros dirigentes" (“Caso lonkos”) (2019): Corte Suprema, 16 mayo 2019, AD 1386-2014. (Pleno, Cúmplase sentencia Corte IDH).

"Remingual Lemui Cristobal con Ilustre Municipalidad de Osorno" (2013): Corte Suprema, Rol 481-2013, 23 septiembre 2013 (Casación fondo).

Tribunal Constitucional Alemán, BVerfGE 7, “Caso Lüth”, 1958.

Tribunal Constitucional, Chile, Rol 2552-2013, 24 diciembre 2015.

Tribunal Constitucional, Chile, Rol 2387-2012, 23 enero 2013.

\section{Normas citadas:}

Convenio 169 de la Organización Internacional del Trabajo (OIT) Sobre Pueblos Indígenas y Tribales en Países Independientes Adoptado por la Conferencia Internacional del Trabajo en Ginebra, el 27 de junio de 1989. Ratificado por Chile el 16 de septiembre de 2008. 
Constitución Política de la República, Decreto Supremo N¹00-2005 (22.09.2005), Fija el texto refundido, coordinado y sistematizado de la Constitución Política de la República de Chile (1980).

Declaración de las Naciones Unidas sobre Derechos de los Pueblos Indígenas. Aprobada por la Asamblea General de la ONU el 13 de septiembre de 2007.

Ley $\mathrm{N}^{\circ} 19.253$ (5.10.1993) Establece normas sobre protección, fomento y desarrollo de los indígenas, y crea la Corporación Nacional de Desarrollo Indígena.

Ley $\mathrm{N}^{\circ} 17.729$ (26.9.1972) Establece normas sobre indígenas y tierras de indígenas. transforma la Dirección de Asuntos Indígenas en Instituto de Desarrollo Indígena. establece disposiciones judiciales, administrativas y de desarrollo educacional en la materia y modifica o deroga los textos legales que señala.

Reglas de Brasilia sobre Acceso a la Justicia de las Personas en condición de Vulnerabilidad" (2008). Disponible en http://www.acnur.org/fileadmin/Documentos/BDL/2009/7037.pdf?view=1. 